NASA Contractor Report 3724

\title{
The Effect of Stress on Ultrasonic
} Pulses in Fiber Reinforced Composites

John H. Hemann and George Y. Baaklini

GRANT NAG3-106 AUGUST 1983

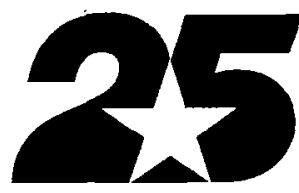

25th Anniversary 1958-1983

\section{N/Sก}


NASA Contractor Report 3724

\section{The Effect of Stress on Ultrasonic Pulses in Fiber Reinforced Composites}

John H. Hemann and George Y. Baaklini Cleveland State University Cleveland, Ohio

\section{N/Sก}

National Aeronautics and Space Administration

Scientific and Technical Information Branch

1983 


\section{INTRODUCTI ON}

This report provides the experimental results obtained by the use of ultrasonic techniques as a non destructive evaluation tool for fiber reinforced composite materials. The report is divided into two parts, because the research was done in two separate periods, in two independent locations, and using two different pulsing systems.

The first part covers the ultrasonic evaluation of a " 0 " degree graphite-epoxy fiber reinforced composite under tensile loading. The research proved that wave speeds are frequency dependent, that attenuation is strongly dependent on tensile stress, and that wave speed is weakly dependent on tensile stress.

The second part is devoted to understanding the dispersion mechanism in thin graphite-epoxy fiber reinforced composite. This dispersion mechanism has to be fully examined and understood in this material in order to sort out the relationships existing among stress, strain, damage, and ultrasonic signals. 


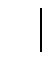


PART I

TABLE OF CONTENTS

CHAPTER

PAGE

I. INTRODUCTION . . . . . . . . . . . . . . 1

II. EXPERIMENTAL PROCEDURE

2.1 Apparatus .................. 3

2.2 Experimental System . . . . . . . . . 7

2.3 Procedure ................. . . 7

III. RESULTS

3.1 Dispersion and Wave Type . . . . . . . . 14

3.2 Attenuation is Strongly Dependent

on Tensile Stress............. . 17

3.2.1 Frequency Domain Results . . . . . . 22

3.2.2 Time Domain Results ... . . . . . 22

3.2.3 Comparison of Results Between
Frequency Domain and Time Domain . . . 25

3.2.3.1 Superposition of Different
Frequencies . . . . . 25

3.2.3.2 Superposition of Different
Modes . . . . . . 35

3.3 Wave Speeds are Weakly Dependent on
Tensile Load . . . . . . . . 35

3.4 Reproducibility............. . 36

IV. CONCLUSION ...................... 45 
vi

PART II

TABLE OF CONTENTS

CHAPTER

PAGE

I. INTRODUCTION .................

II. LAMB WAVE EXCITATION

2.1 Transducer/Specimen Testing Configurations. . .

2.2 Experimental System . . . . . . . . . 54

2.3 Materials Tested ........... 56

2.4 Procedure ............... 56

III. EXPERIMENTAL RESULTS

3.1 Dispersion in the Case of Normal Incidence . . 59

3.2 The use of Plastic Wedges for $0^{\circ}<\theta<90^{\circ}$. . 61

3.3 Axial Incidence Waves, $\theta=90^{\circ}$........ 63

3.4 Lamb Wave Propagation in Aluminum . . . . . 66

IV. CONCLUSIONS .................. 70

BIBLIOGRAPHY .................. 71 
PART I

ULTRASONIC EVALUATION

OF A "O" DEGREE GRAPHITE-EPOXY COMPOSITE

UNDER TENSILE LOADING. 23 
viii

\section{ABSTRACT}

An Acoustical-U1trasonic Technique was used to demonstrate that relationships exist between changes in attenuation of stress waves and tensile stress for an 8-ply "0" degree graphite-epoxy fiber reinforced composite. All tests were conducted in the 7 inear range of the material for which no mechanical or macroscopic damage was evident. Changes in attenuation were measured as a function of tensile stress in the frequency domain and in the time domain. Stress wave propagation in these specimens was dispersive, i.e., the wave speed depends on frequency. Wave speeds varied from $267400 \mathrm{~cm} / \mathrm{sec}$ to $680000 \mathrm{~cm} / \mathrm{sec}$ as the frequency of the signal was varied from $150 \mathrm{KHZ}$ to $1.9 \mathrm{MHZ}$ which strongly suggests that flexural/ Lamb wave modes of propagation exist. The magnitude of the attenuation changes depended strongly on tensile stress. It was further observed that the wave speeds increased slightly for all tested frequencies as the stress was increased. 
CHAPTER I

INTRODUCTION

The first practical application of ultrasonics for test metal bodies for internal defects was done by the Russian Sokolor' in 1934. He was using a through transmission technique, transmitting the sound into the body under test, utilizing a piezo-electrical crystal, and was detecting this sound on the opposite side of the body, adopting a second similar piezo-electrical crystal. Independently in this country as well as in England ultrasonic development started about 1940.

After World War II the measurement of stress wave attenuation by means of ultrasonic nondestructive evaluation (NDE) techniques evolved gradualiy to a more complete and desirable state. In the 50's NDT techniques were used for flaw detection and for measuring the thickness of material where onty one side was accessible. Also automatic monitors were adopted in the instrumentation of u7trasonic testing. In 1954, Firestone ${ }^{2}$ developed the principle for the impulse echo devices. In 1956, Truell and Hikata ${ }^{3}$ established the relationship between attenuation in aluminum and the number of fatigue cycles. In 1960 ultrasonic determination of elastic constants of metals at elevated temperature was achieved by Levitt and Martin ${ }^{4}$. U1trasonic pulse-echo techniques have been used by evaluating thickness, bonding, and corrosion 5 .

Recent7y, (NDE) techniques have gone further than detecting flaws; Vary et.a1. ${ }^{6-11}$ have demonstrated that a correlation does exist between u1trasonic attenuation and mechanical and strength properties of metals, ceramics, and fiber composites. Also Williams et.al. ${ }^{12,13}$ have shown that ultrasonic 
attenuation is an indicator of a fatigue life of graphite-epoxy composites. UTtrasonic measurements in the area of composite material, up to now, have provided a nondestructive means for measuring variations in strength related properties, predicting interlaminar shear strength of fiber composite laminates, and ranking composite structures according to strength.

This research will investigate how well (NDE) techniques describe stress related effects. An ultrasonic attenuation study, of a stress wave propagating through a " 0 " degree graphite-epoxy fiber reinforced composite specimen subjected to tensile loads, was performed. This paper will provide not oniy qualitative data, but also quantitative data, showing the relationships that exist between changes in attenuation of stress waves and tensile stress for the 8-ply "0" degree specimen under consideration. Tensile testing was done in the linear range of the material, where linearity is defined by constant slope of the stress-strain curve in the range of the test conducted. Wave speeds were also measured showing that stress wave propagation is dispersive.

This thesis will demonstrate that:

1. Dispersion does occur, i.e., wave speeds are frequency dependent.

2. The attenuation is strongiy dependent on tensile stress.

3. The wave speed is weakly dependent on tensile stress. 
CHAPTER II

\section{EXPERIMENTAL PROCEDURE}

The specimen used was an eight-ply "0" degree graphite-epoxy fiber reinforced composite. An AS graphite fiber and a PR-288 exposy resin have been used to construct an AS/PR-288 preimpregnated fiber-resin ply. The fibers were coated with a polyvinyl alcohol to enhance fiber-matrix interface strength properties. A schematic of the unidirectional composite is stown in Figure 1. Physical properties of the specimen are given in Table I below: 8

TABLE I - DESCRIPTION OF THE TENSILE SPECIMEN LVII

\begin{tabular}{|c|c|c|c|}
\hline Ply angle, $\operatorname{deg}^{a}$ & {$[0] 8$} & Ultimate strength, $\mathrm{GP}_{\mathrm{a}}$ & 1.24 \\
\hline Fiber coating & PVA & Tensile modulus $\mathrm{E}, \mathrm{GP}_{\mathrm{a}}$ & 110 \\
\hline Gage length, $\mathrm{cm}$ & 12.7 & Poisson's ratio, & .283 \\
\hline Thickness $t, \mathrm{~cm}$ & .1384 & Fiber fraction $x^{b}, f_{f}$ & 69.2 \\
\hline Density $0,9 / \mathrm{cm}^{3}$ & 1.584 & Stress wave factor NSW & .853 \\
\hline \multicolumn{3}{|c|}{$\begin{array}{l}\text { a Fiber angles relative to tensile axis in AS graphite, } \\
\text { PR-288 epoxy composite }\end{array}$} & \\
\hline
\end{tabular}

\subsection{APPARATUS:}

A schematic of specimen and transducers in uitrasonic through transmission testing was shown in Figure 2 . 


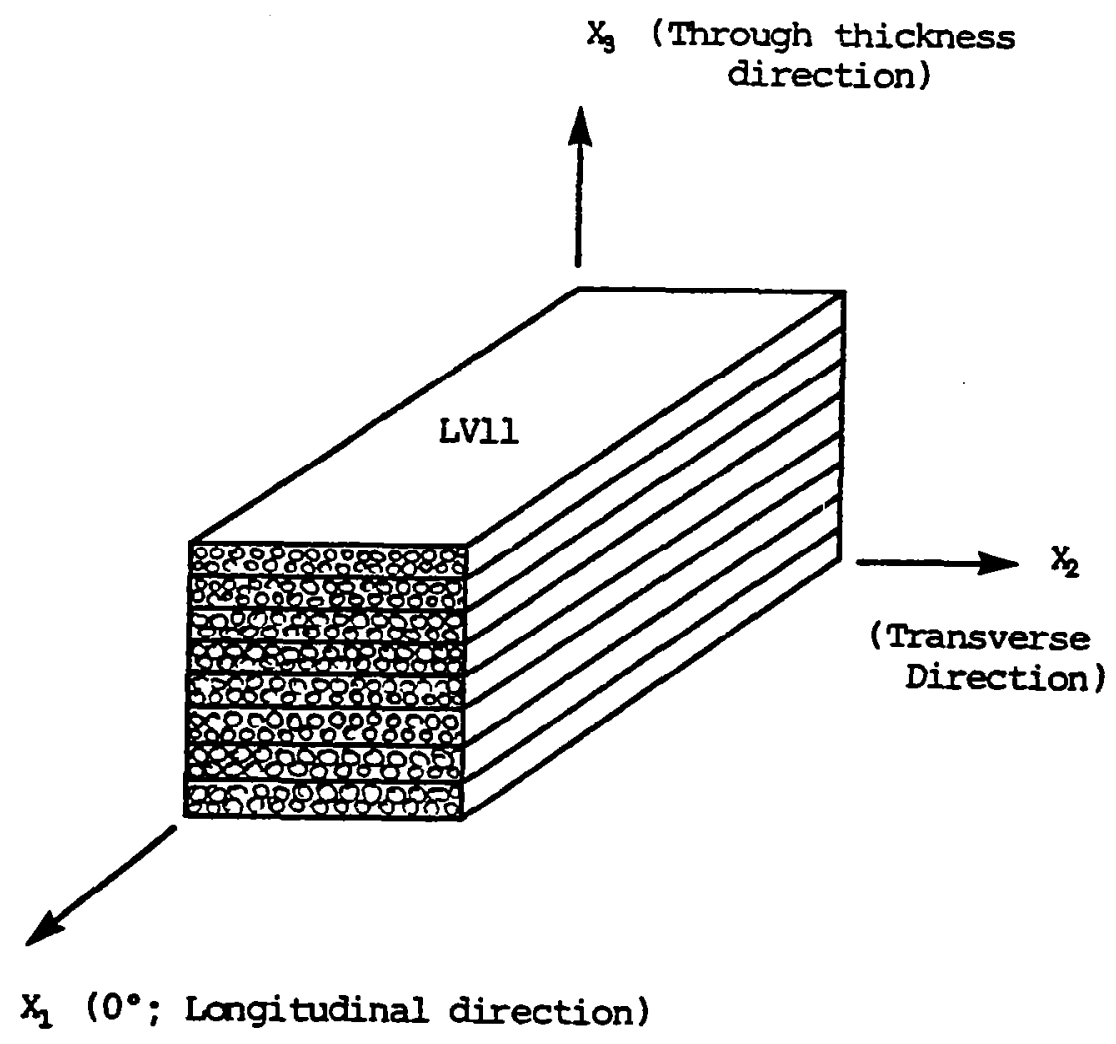

FIG. 1 - PRINCIPAL DIRECTIONS OF

"O" DEGREE GRAPHITE

EPOXY SPECIMEN 


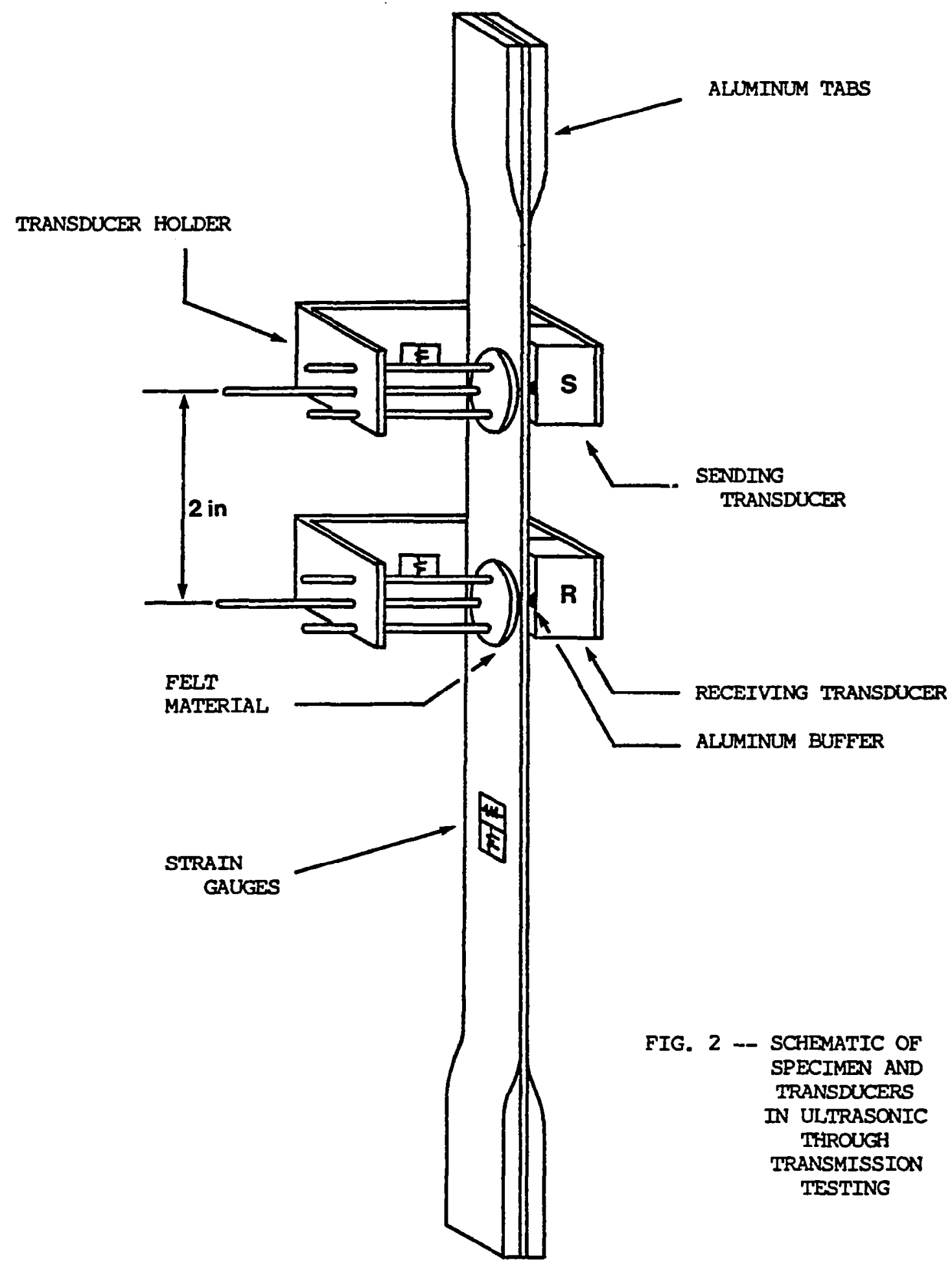


Panametric transducers as well as Dunegan transducers were used in this experiment. Their properties are tabulated in Table II.

TABLE II - THE PROPERTIES OF THE TRANSDUCERS

$\begin{array}{lcccc}\text { Frequency, MHZ } & 2.25 & 1.0 & .438 & .226 \\ \text { Mode1 } & \begin{array}{c}\text { Panametric } \\ \text { V314 }\end{array} & \begin{array}{c}\text { Panametric } \\ \text { A306 }(-)\end{array} & \begin{array}{c}\text { Dunegan } \\ \text { S750B }\end{array} & \begin{array}{c}\text { Dunegan } \\ \text { S140B }\end{array} \\ \begin{array}{l}\text { Transmits } \\ \text { \& Receives }\end{array} & \begin{array}{c}\text { Longitudinal } \\ \text { Waves }\end{array} & \begin{array}{c}\text { Longitudinal } \\ \text { Waves }\end{array} & \begin{array}{c}\text { Longitudinal } \\ \text { Waves }\end{array} & \begin{array}{c}\text { Longitudinal } \\ \text { Waves }\end{array} \\ \text { Type } & \text { Broad-band } & \text { Broad-band } & \text { Resonant } & \text { Resonant }\end{array}$

A7uminum semicylindrical buffers of $3.157 \mathrm{~mm}$ (.125 in) diameter were attached to the transducers in order to:

a. Provide a line contact of length $12.7 \mathrm{~mm}$ (.5 in) which the width of the specimen.

b. Prevent bending from occurring as pressure was applied to the transducers by the transducer holders.

c. Place the sending and the receiving transducer at specified location.

Strain gauges were mounted on the specimen on both faces to measure the strain when tensile testing was performed. Strain gauges were $0^{\circ}$ and $90^{\circ}$ orthogonal back-to-back. Also strain gauges were installed onto the transducer holders to measure the pressure applied to the transducers. Williams, et. al. 13 defined and measured a "saturation pressure" which is required for reproducible coupling of transducer to specimen; this pressure was monitored by the strain-gauged transducer holders.

An ultragel II ultrasonic couplant was used between the aluminum buffer and the specimen. A very thin coating of couplant was used where effects of thickness of the couplant were neglected. A felt material was used on the backside of the transducer holder to insure that energy did not enter the transducer holder from the specimen. 


\subsection{EXPERIMENTAL SYSTEM}

The experimental system is shown in Figure 3 and the description of the main equipment is tabulated in Table III.

TABLE III - DESCRIPTION OF THE MAIN EQUIPMENT

\section{IDENTIFICATION $\quad$ FUNCTION}

Tensile

Parts:
a - Honeywe11 machine
a - Strain and load indicator
b - Riehle machine
b - Tensile machine

U1trasonic

Parts:

$$
\begin{gathered}
\text { a - } \\
\text { bectrum analyser } \\
\text { b - Panametric Pulser } \\
5052 \mathrm{P} / \mathrm{R}
\end{gathered}
$$$$
\text { a - Outputs the frequency spectrum }
$$$$
\text { of the trarismitted pulse }
$$$$
\text { b - Provides a voltage pulse to }
$$$$
\text { sending transducer }
$$$$
\text { c - Provides band-pass filtering of }
$$
transmitted pulse

d - Amplifies and band-pass filters transmitted pulse

3 - Records the input pulse and the transmitted pulse in real time

\subsection{PROCEDURE}

An ultrasonic wave was transmitted into the specimen by a sending transducer. Two inches away in the longitudinal direction, and on the same face, a receiving transducer was placed to sense the stress wave energy traversing the specimen. The receiving transducer output was displayed on the oscilloscope for real time analysis and on the spectrum analyser for frequency analysis.

The specimen, mounted in a tensile machine where care was taken to avoid off-axis loading or twisting, was pulled at an initial loading rate of approximately $17 \mu \mathrm{m} / \mathrm{sec}(.04 \mathrm{in} / \mathrm{min})$ to set the grips. After this 
SCOPE

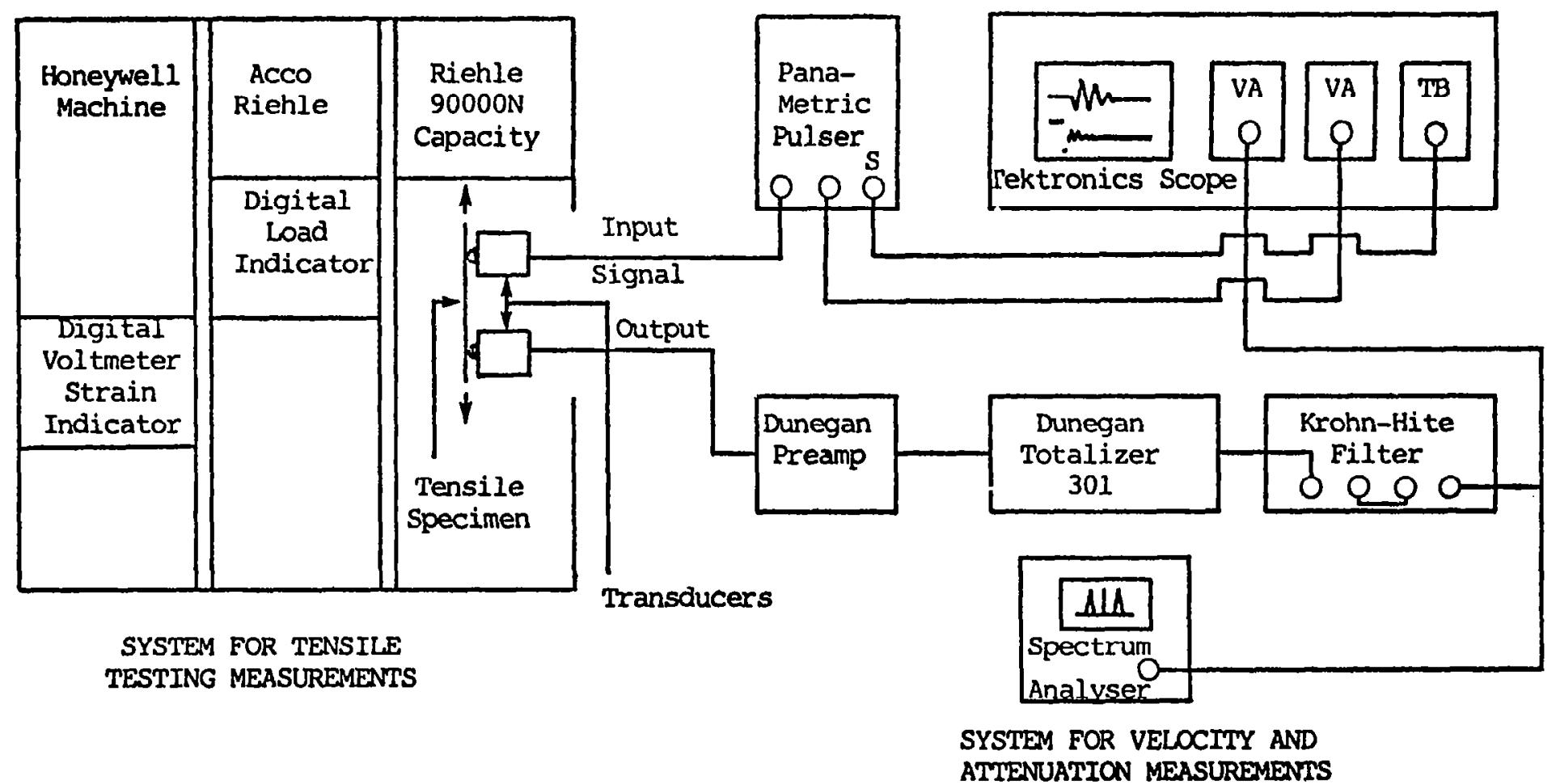

FIG. 3 -- EXPERIMENTAL SYSTEM-1 
initial loading to about $445 \mathrm{~N}$ (100 $\mathrm{lbf}$ ) which was the reference load for attenuation measurements and change in attenuation measurements, further loading was done at mean rate of $4.2 \mu \mathrm{m} / \mathrm{sec}(.01 \mathrm{in} / \mathrm{min})$.

The load was increased to $3560 \mathrm{~N}$ ( $800 \mathrm{lbf}$ ), 6675N (1500 lbf), and in some experiments to $13350 \mathrm{~N}$ ( $3000 \mathrm{lbf}$ ) successively. Then the load was decreased to $6675 \mathrm{~N}, 3560 \mathrm{~N}$, and $445 \mathrm{~N}$. At the same time strain-load data was generated, photographs of the stress wave output and the frequency output were taken.

The loading-unloading cycle was repeated five to seven times for each setting of independent variables (Table IV), which usually occurred within a two hour period. The number of cycles that were required was dictated by the reproducability of the attenuation changes.

Typical output signals are shown in Figure 4 and Figure 5 for an entire loading-unloading cycle.

TABLE IV - SETTING OF INDEPENDENT VARIABLES

$\begin{array}{ccccc}\text { Frequency }^{\mathrm{a}} & \begin{array}{c}\text { Sending }^{\mathrm{b}} \\ \text { Transducer }^{\mathrm{N}}\end{array} & \begin{array}{c}\text { Receiving }^{\mathrm{b}} \\ \text { Transducer }^{\mathrm{N}}\end{array} & \begin{array}{c}\text { Number } \\ \text { of Tests }\end{array} & \begin{array}{c}\text { Filter } \\ \text { Setting }\end{array} \\ 1.9^{\mathrm{e}} & 2.250 & 2.250 & 2 & 2 \mathrm{MHZ} / 2 \mathrm{MHZ} \\ .850 & 1.000 & .439 & 2 & 1 \mathrm{MHZ} / 1 \mathrm{MHZ} \\ .250 & 2.250 & 1.000 & 2 & .3 \mathrm{MHZ} / .4 \mathrm{MHZ} \\ .180 & 1.000 & .439 & 2 & .2 \mathrm{MHZ} / .2 \mathrm{MHZ} \\ .150 & .439 & .226 & 2 & .1 \mathrm{MHZ} / .1 \mathrm{MHZ}\end{array}$

a - From spectro-analysis of the output signal (in $M H Z$ )

b - Frequency of transducer type (in MHZ)

c - Number of independent tests performed in different days

d - Krohn-hite filter was used passing everything $\geq$ to $x$ and $\leq$ to $y$ in the setting $x / y$.

e - Also $1.7 \mathrm{MHZ}$ was displayed in the same output with $1.9 \mathrm{MHZ}$. 


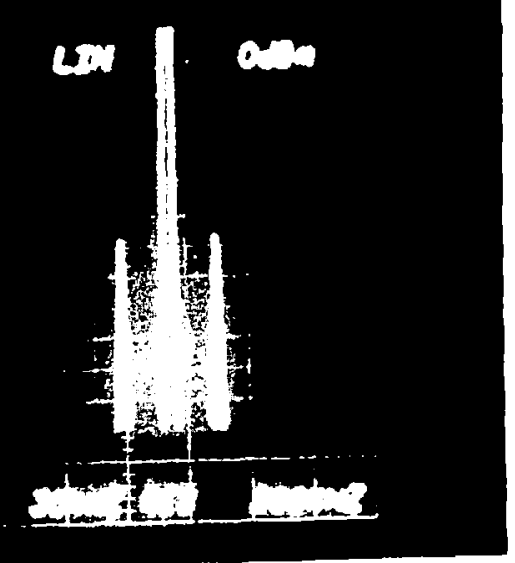

a. At $507 \mathrm{~N}$

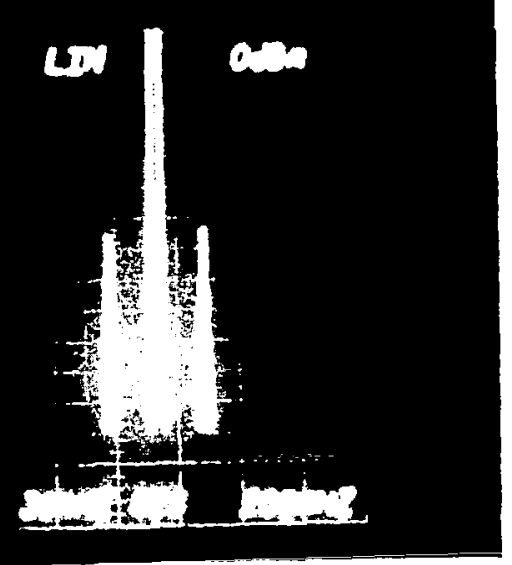

b. At $3658 \mathrm{~N}$

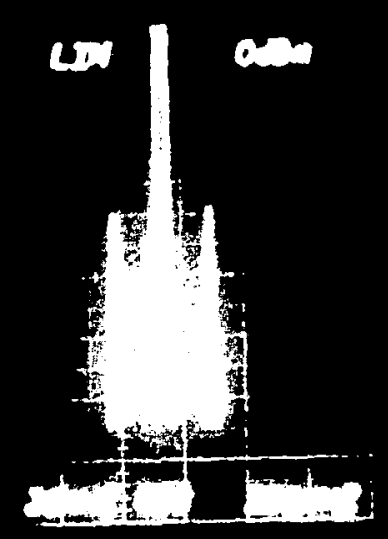

c. At $6826 \mathrm{~N}$

FIG. 4 - ULTRASONIC PULSE ATTENUATION VERSUS LOAD of the $150 \mathrm{KHZ}$ in the Frequency Domain 


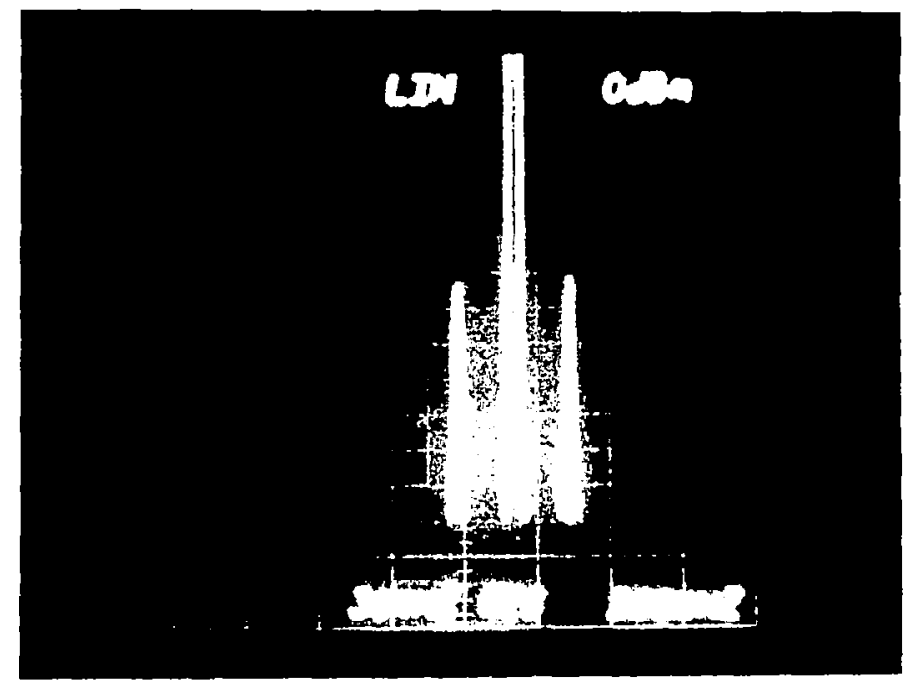

d. At $3617 \mathrm{~N}$

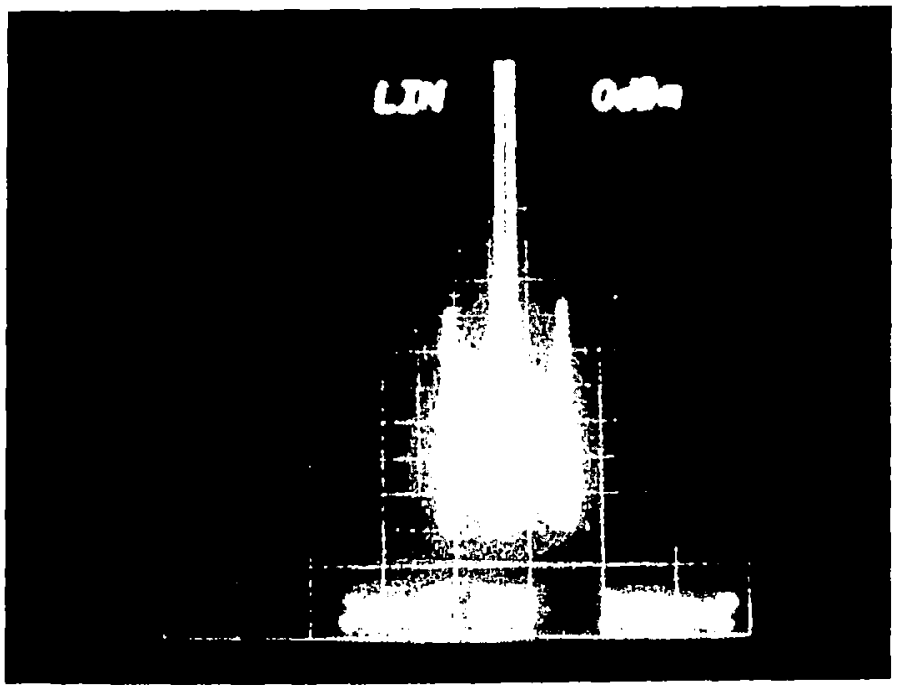

e. At $525 \mathrm{~N}$

FIG. 4 - ULTRASONIC PULSE ATTENUATION VERSUS LOAD of $150 \mathrm{KHZ}$ in the Frequency Domain 


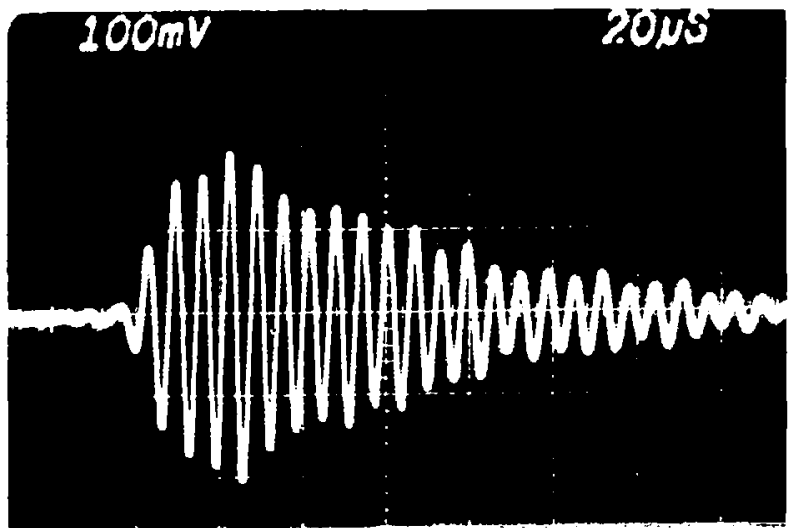

a. At $507 \mathrm{~N}$

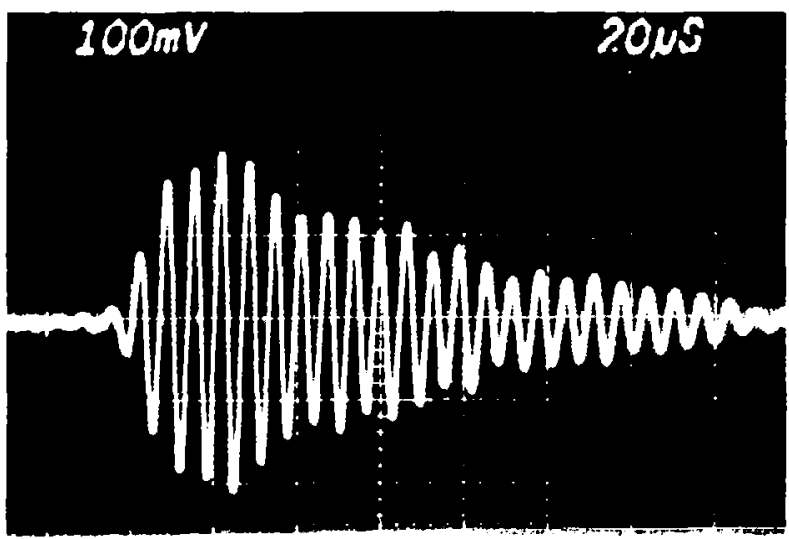

b. At $3658 \mathrm{~N}$

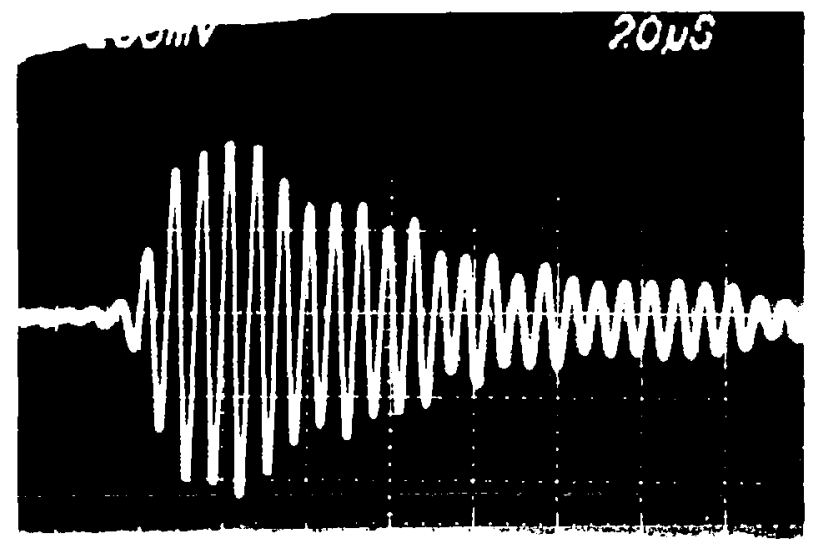

c. At $6826 \mathrm{~N}$

FIG. 5 - ULTRASONIC PULSE ATTENUATION VERSUS LOAD of the $150 \mathrm{KHZ}$ in the Time Domaine 


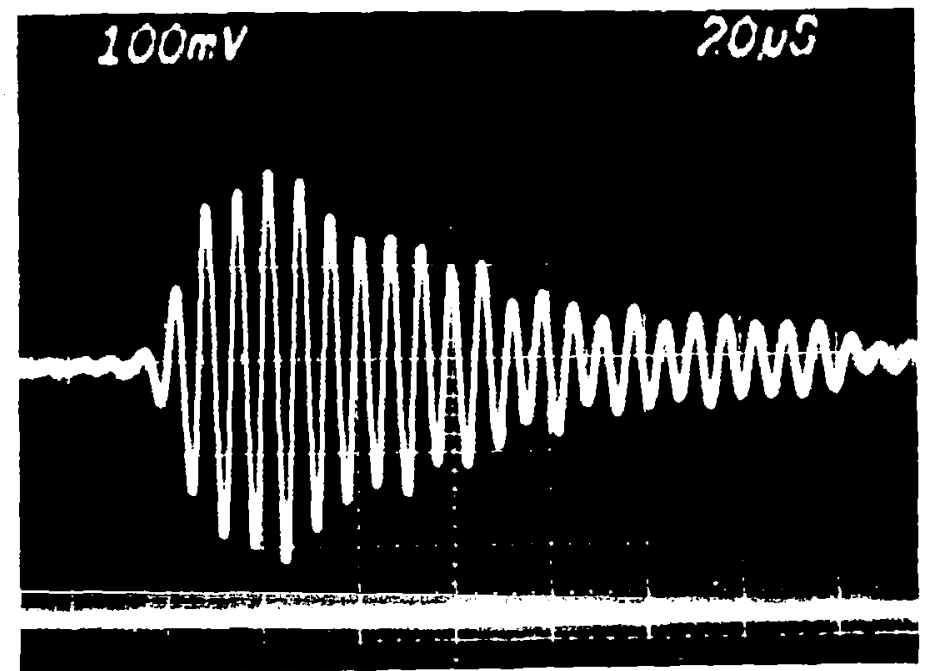

d. At $3617 \mathrm{~N}$

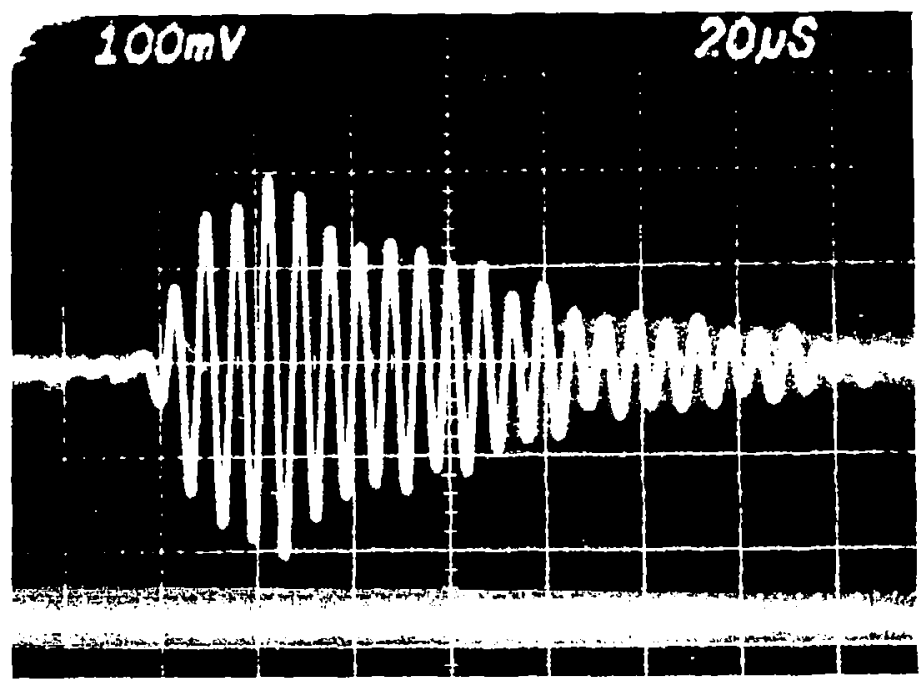

e. At $525 \mathrm{~N}$

FIG. 5 - ULTRASONIC PULSE ATTENUATION VERSUS LOAD OF $150 \mathrm{KHZ}$ in the Time Domain 
CHAPTER III

\section{RESULTS}

In this experimental research many observations were made concerning how various parameters effected the ultrasonic output; only a few were examined and are presented in this paper because of time, equipment, and experimental system limitations. This chapter will present the dispersion phenomenon and the wave type, the attenuation as related to tensile load, and the wave speed as related to tensile load; the specimen was a "0" degree graphite-epoxy fiber reinforced composite. Also reproducibility of results will be treated at the end of this chapter.

\subsection{DISPERSION AND WAVE TYPE}

Dispersion is understood to mean that wave speeds are frequency dependent. From the data collected and the measurements taken, a graph was plotted showing speed versus frequency for the specimen under study in Figure 6. The wave speed was determined by measuring the delay time between the output wave front and input wave front over fixed distance. The graph shows that the wave velocity along the longitudinal fiber is frequency dependent. Wave speeds varied from $267400 \mathrm{~cm} / \mathrm{sec}$ to $680000 \mathrm{~cm} / \mathrm{sec}$ as the frequency of the signal was varied from $150 \mathrm{KHZ}$ to $1.9 \mathrm{MHZ}$.

There are actually two types of dispersions. First is viscoelastic dispersion due to viscoelastic properties of the material. Second is a

geometric dispersion due to the dimensions of the material. Williams ${ }^{13}$ demonstrated that there is no viscoelastic dispersion in the graphite-epoxy composite for longitudinal and shear wave velocities in the range tested: Shear wave velocities tested in the range of 0.48 to $3.0 \mathrm{MHZ}$ and longitudinal 


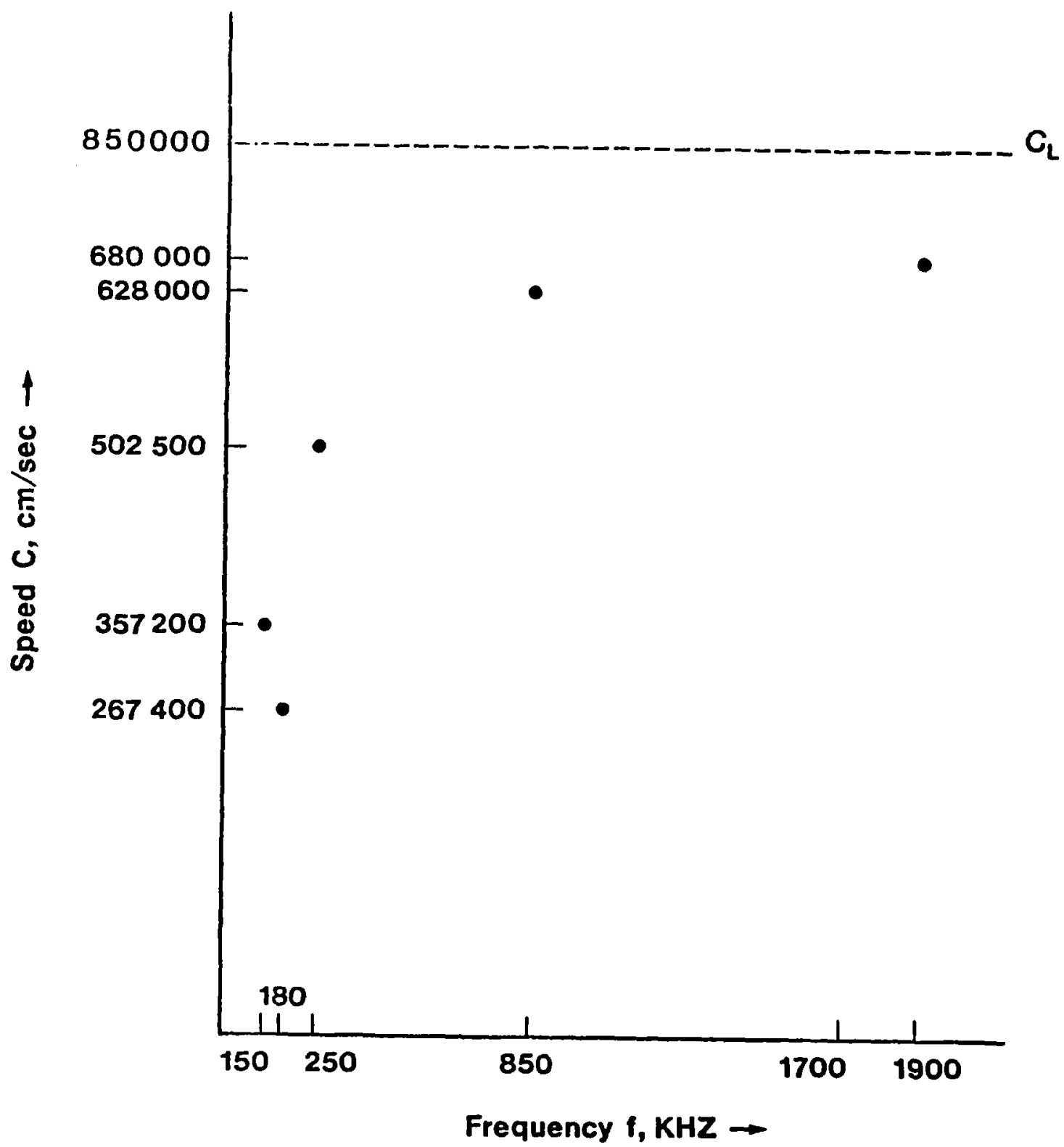

FIG. 6 WAVE SPEED VERSUS FREQUENCY 
wave velocities tested in the range of $0.225 \mathrm{MHZ}$ to $5 \mathrm{MHZ}$. The frequency range of results presented in this paper is 0.15 to $1.9 \mathrm{MHZ}$, which is very close to the range of Williams' result.

For the wave propagating in the $x_{1}$ direction and having a particle motion in the $x_{1}$ direction, William ${ }^{13}$ measured the longitudinal wave speed and found it to be 8.5 to $10^{5} \mathrm{~cm} / \mathrm{sec}$. This wave speed $C_{L}$ is plotted in Figure 6 and is used as a comparison since the material used in William's research is very similar to the material used in the researct. reported here.

By comparing $C_{L}$ to the velocities obtained in this experiment as shown in Figure 6 , one can see that the wave velocities measured were not longitudinal wave velocities. The sending transducer inputs a longitudinal wave perpendicular to specimen which, because of many reflections, becomes a wave propagating along the length of the specimen. During this propagation shear waves are formed due to the reflections and interact with longitudinal waves. This interaction of waves propagating along a thin specimen produces Lamb waves ${ }^{14}$. Dispersion does occur in the propagation of flexural/Lamb waves ${ }^{15}$.

Lamb wave propagation may exist in a multimode state at a given frequency producing a finite number of wave speeds to exist simultaneousiy. Because of experimental limitations, this research could not define which mode (Figure 6) and how many modes were superimposed upon each other, but this paper recognized 
the possible existence of different modes simultaneously in the stress wave output.

\subsection{ATTENUATION IS STRONGLY DEPENDENT ON TENSILE STRESS}

The relationship between attenuation and tensile stress was investigated by measuring the pulse amplitude change in the time domain as well as in the frequency domain. The tensile load applied to the specimen was in the linear range of the material where linearity was based on the constant slope of the stress-strain curve shown in Figure 7.

In order to understand the analysis adopted in this chapter, a graph is shown in Figure 9 which refers to general but realistic pulse. Ard this graph is complemented by the following explanation:

The percent change in amplitude in the time domain (Figure 8) was calculated in the following manner -- the peak to peak amplitude $A_{S}$ for a spike was measured at every specified load $P_{S}$; then the difference between $A_{S}$ and the reference peak to peak amplitude $A_{R}$ at the reference load $P_{R}$ (first $445 \mathrm{~N}$ load reached in the cycling process) was multiplied by the inverse of $A_{R}$ and by one hundred which gave the percent change in amplitude at $P_{S}$. Most of the time though, this analysis was applied to $n$ number of spikes in a stress wave output at $P_{S}$ :

\% amplitude change at $P_{S}=\left[\left(\begin{array}{llll}\sum_{i=1}^{n} & A_{S} & -\sum_{i=1}^{n} & A_{R}\end{array}\right] / \sum_{i=1}^{n} A_{R}\right] \times 100$ 


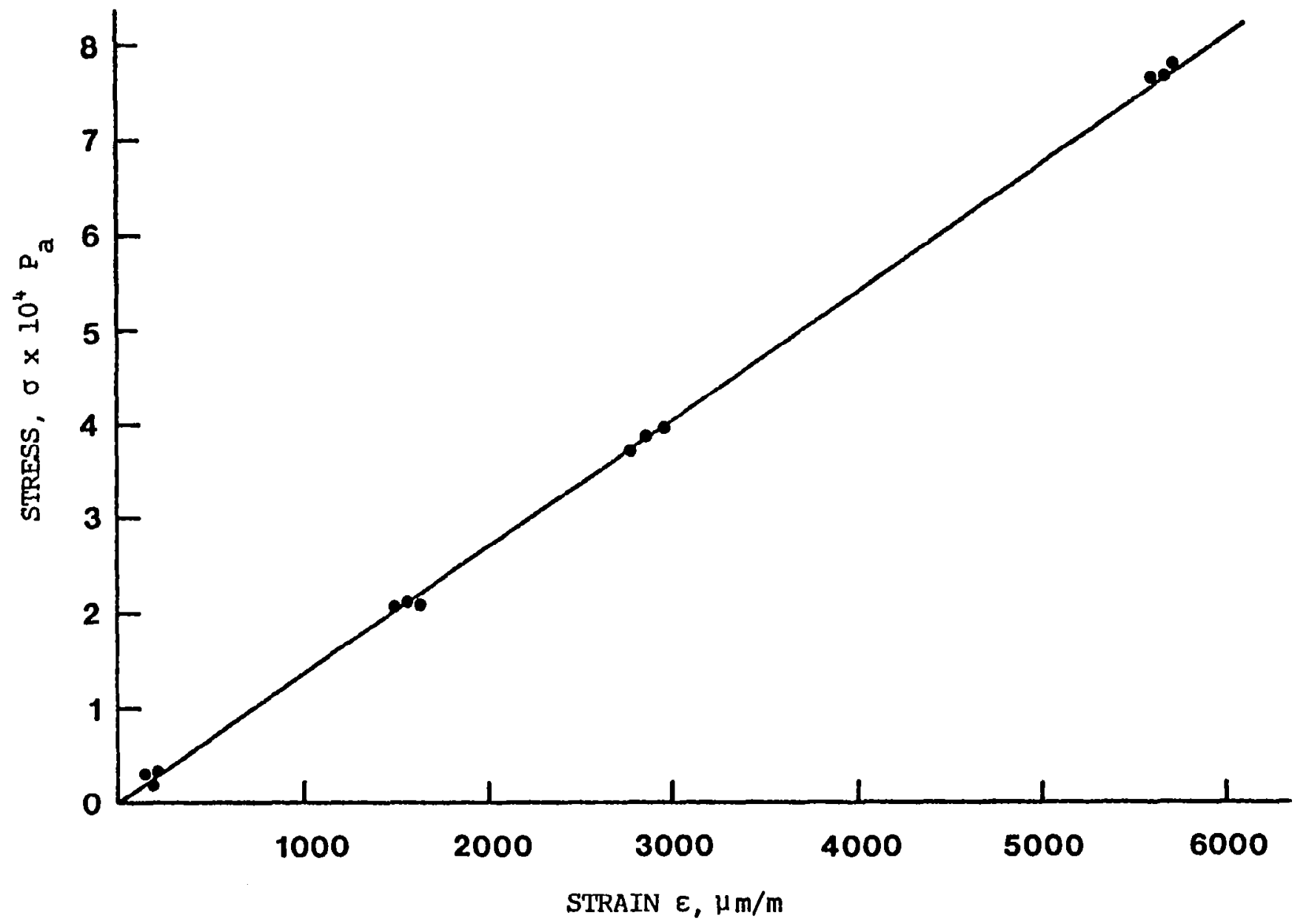

FIG. 7 - AXIAL STRESS VERSUS AXIAL STRAIN 

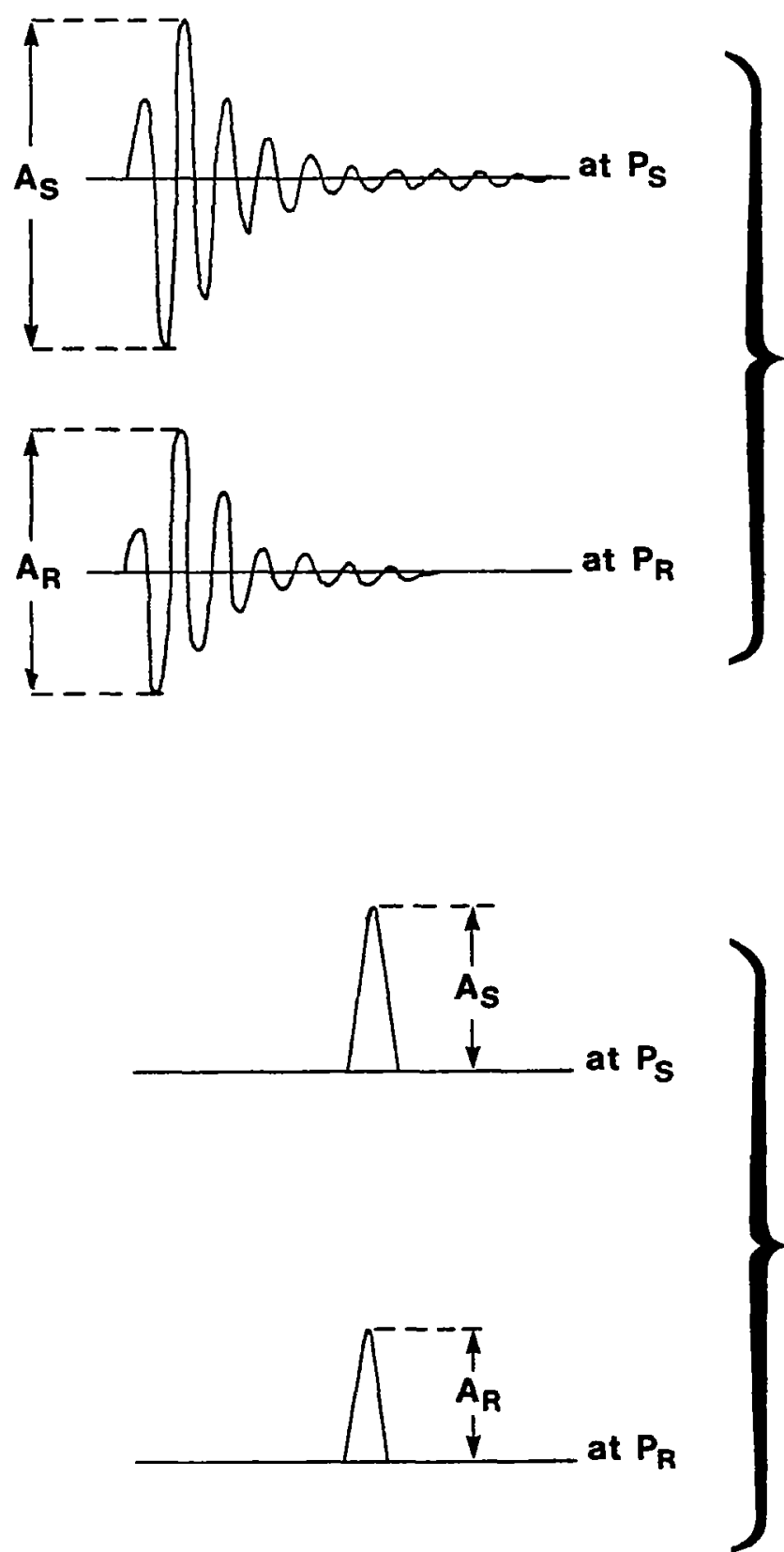

FREQUENCY OUTPUT

IN THE FREQUENCY DOMAIN

FIG. 8 SCHEMATIC OF $A_{S}$ AND $A_{R}$ IN THE TIME DOMAIN AND IN THE FREQUENCY DOMAIN 
where $P_{S}=$ Specified 1oad $445 N, 3560 N$, or $6675 N \ldots$

$i=1, \ldots, n$. Where $n$ is the number of spikes.

$A_{S}=$ Vertical measurement from peak to peak of a specified spike when a specified load is applied. $\begin{aligned} & A_{R}= \text { Vertical measurement from peak to peak of a reference } \\ & \text { spike when the reference load is applied. }\end{aligned}$

The number of spikes chosen was dictated by observing which group of spikes behaved in a similar way and were of the same frequency.

The same analysis procedure was applied to the frequency domain response (Figure 8 ), the only difference was that only one spike existed at each frequency, and $A_{S}$ or $A_{R}$ would be the amplitude. Consequently, Equation One becomes:

$\%$ amplitude change at $P_{S}=\left[\left(A_{S}-A_{R}\right) / A_{R}\right] \times 100 \quad$ Equation 2

Two different phenomenon were observed as the load was cycled. First, during the first few cycles of loading the relationships between amplitude changes and load shifted upward from line A of Figure 9. After 3 or 4 cycles the shifting ceased and the data followed line $C$; the data being contained in the scatter bandwidth B. Second, the percent amplitude change was behaving linearly, increasing or decreasing depending on the frequency of the output signal, when tensile loads were increasing. Figure 9. 


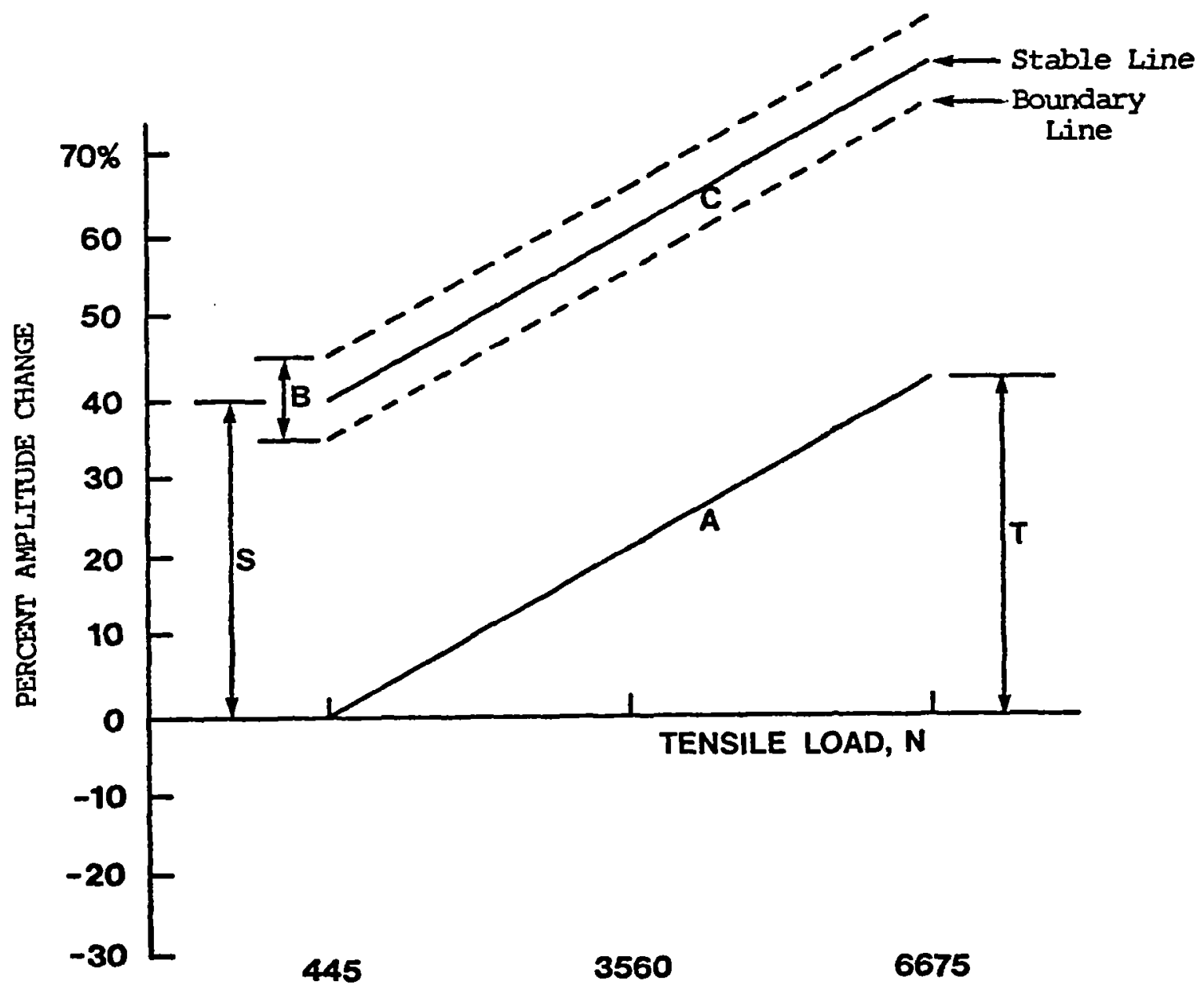

FIG. 9 -- GRAPH DESCRIBING ANALYSIS PROCEDURE

$$
\begin{array}{ll}
\mathbf{T}=\text { Total change } & A=\text { First cycle line } \\
B=\text { Band width } & C=\text { Stable cycle line } \\
S=\text { Shift } &
\end{array}
$$




\subsubsection{FREQUENCY DOMAIN RESULTS}

Figure 10 shows the relationship between the percent change in amplitude versus tensile load for the six frequencies under consideration in the frequency domain. It is approximately a linear relationship, increasing with load for the $150,180,250$ and $1900 \mathrm{KHZ}$, and decreasing when load is increasing for the 850 and $1700 \mathrm{KHZ}$, which demonstrates that attentuation is not only dependent on tensile load, but it is also frequency dependent. Table $V$ describes shift, $B / 2$ and $T$ for every frequency under study.

\section{TABLE $V$ - SHIFT, BANDWIDTH, AND TOTAL CHANGE FOR EVERY FREQUENCY UNDER CONSIDERATION}

$\begin{array}{rrrr}f_{K H Z} & S & B / 2 & T \\ 150 & & & \\ 180 & 13 & 3 & 12 \\ 250 & 16 & 5 & 8 \\ 850 & 13 & 4 & 20 \\ 1700 & 28 & 7 & 28 \\ 1900 & 48 & 5 & 20 \\ & 20 & 8 & 25\end{array}$

\subsubsection{TIME DOMAIN RESULTS}

Figure 11 shows the relationship between the percent change in amplitude versus tensile load for the frequencies under consideration. Table VI shows $B, S$, and $T$ for the time domain results which may be compared with the frequency domain results of Table $V$.

TABLE VI - BEHAVIOR OF FREQUENCIES IN THE TIME DOMAIN

$\begin{array}{cccr}f_{K H Z} & S & B / 2 & T \\ 150^{b} & & & \\ 150^{a} & 14 & 3 & 14 \\ 180 & 0 & 6 & 10 \\ 250 & 13 & 4 & 5 \\ 850 & 11 & 5 & 18 \\ 1900,1700 & 14 & 6 & 16 \\ & 20 & 3 & 8\end{array}$




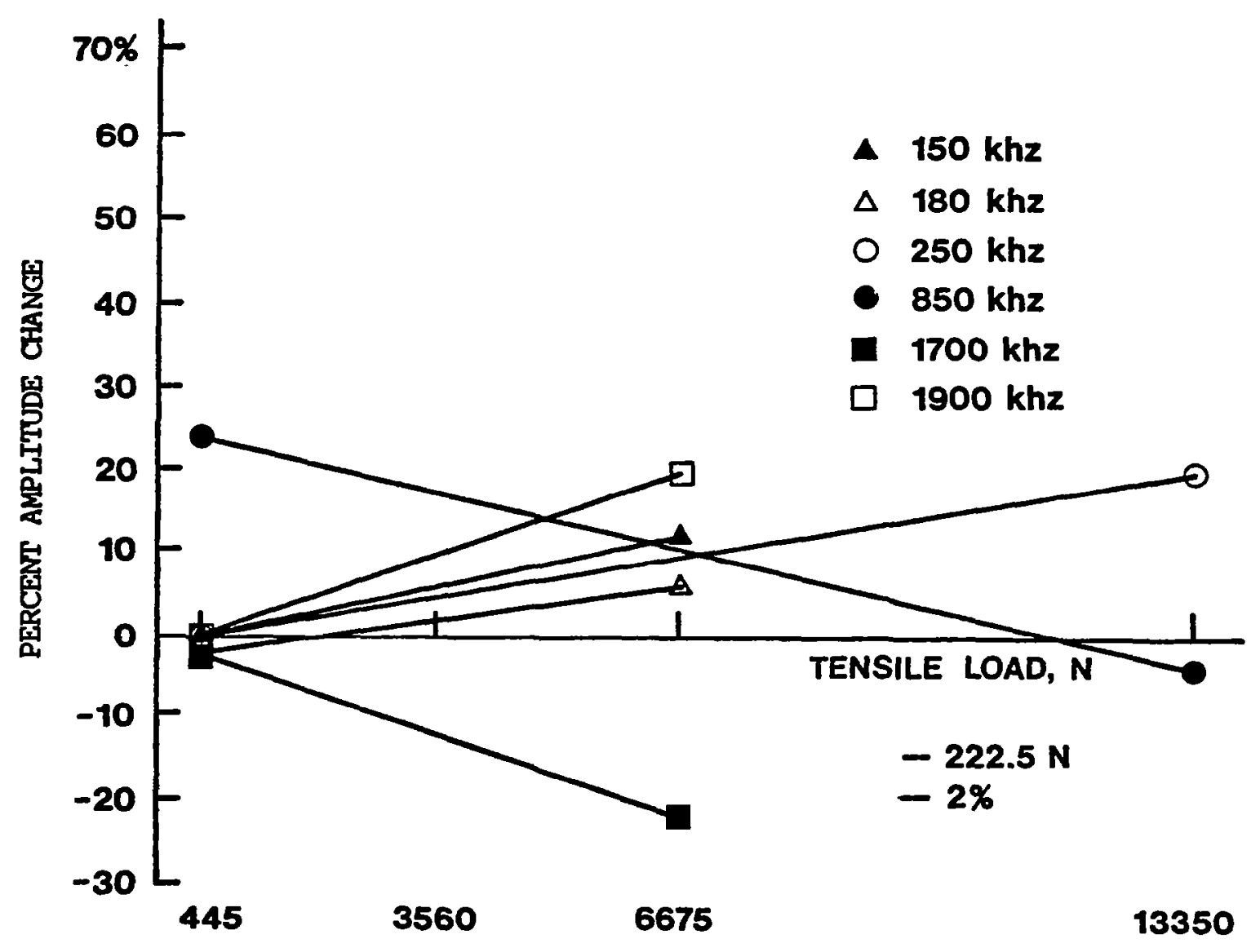

FIG. 10 - PERCENT CHANGE IN AMPLITUDE VERSUS TENSILE LOAD IN THE FREQUENCY DOMAIN

- Note all lines in this graph are of "A" type (See Fig. 9) 


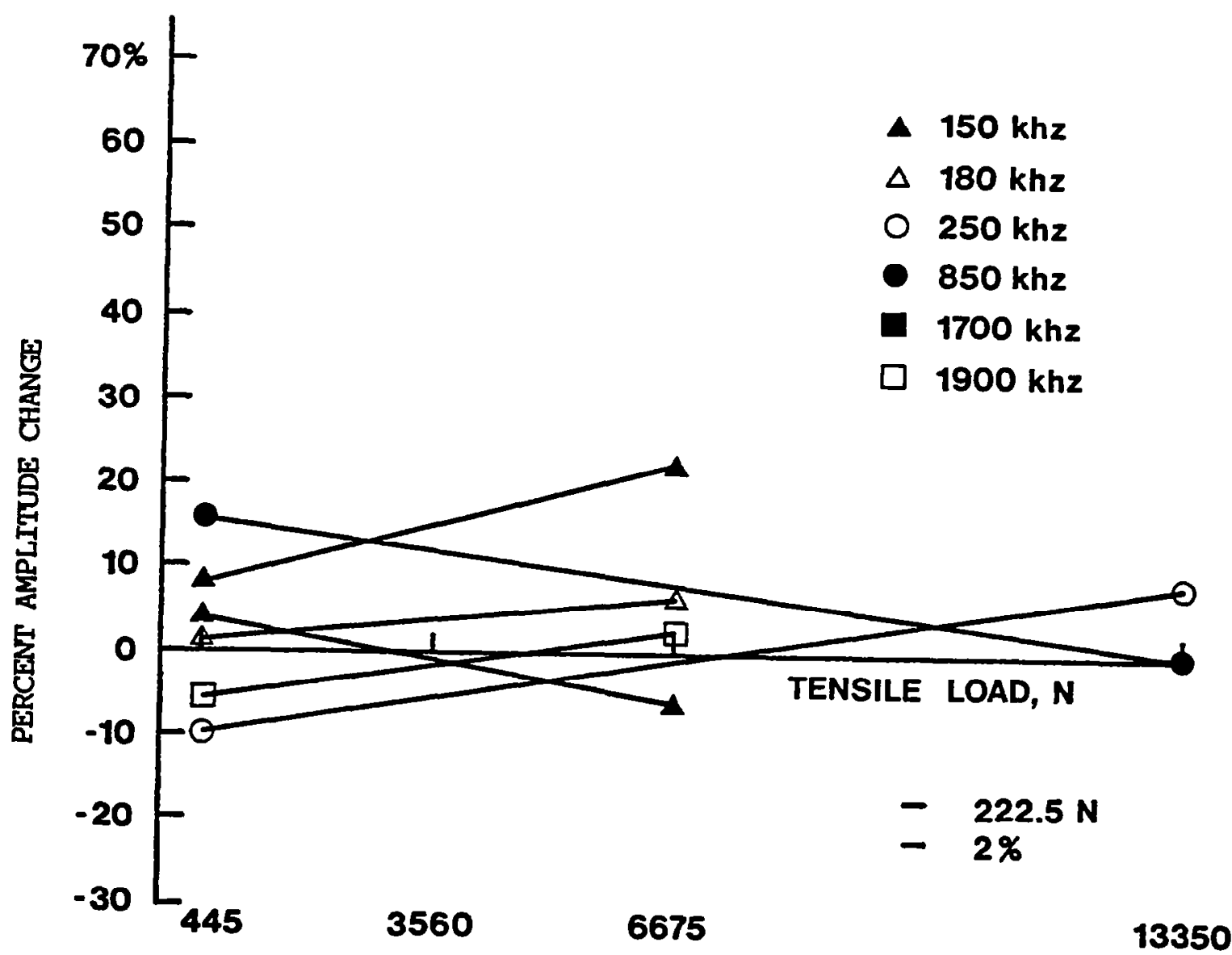

FIG. II -- PERCENT CHANGE IN AMPLITUDE VERSUS TENSILE LOAD IN THE TIME DOMAIN

- Note all lines in this graph are of "A" type (See Fig. 9) 
The on 1y exception was the $150 \mathrm{KHZ}$ case where in experiment a, a definite amplitude increase with load was observed, and in experiment b, a definite decrease in amplitude was seen when load was increased. Photographs for the same cycle in both domains are given in Figure 12 and in Figure 13 for the second experiment which could be compared to the photographs in Figure 4 and Figure 5 in Chapter 2.

\subsubsection{COMPARISON OF RESULTS BETWEEN FREQUENCY DOMAIN AND TIME DOMAIN}

Comparing results from both domains has helped not only to show that both domains behaved in the same way in terms of total energy analysis, but also has helped to observe the presence of superposition of different frequencies as well as of different modes in the stress wave output in the time domain.

\subsubsection{SUPERPOSITION OF DIFFERENT FREQUENCIES}

An extensive calculation on individual spikes was done in the case of the 1.9 and $1.7 \mathrm{MHZ}$ experiment, and showed that some spikes were increasing with load while some others were decreasing. This behavior was analysed in comparison with the behavior of the two frequencies 1.9 and $1.7 \mathrm{MHZ}$ in the frequency domain, and results were tabulated in Table VII and Table VIII. Also photographs were presented for this case in Figure 14 and Figure 15. 


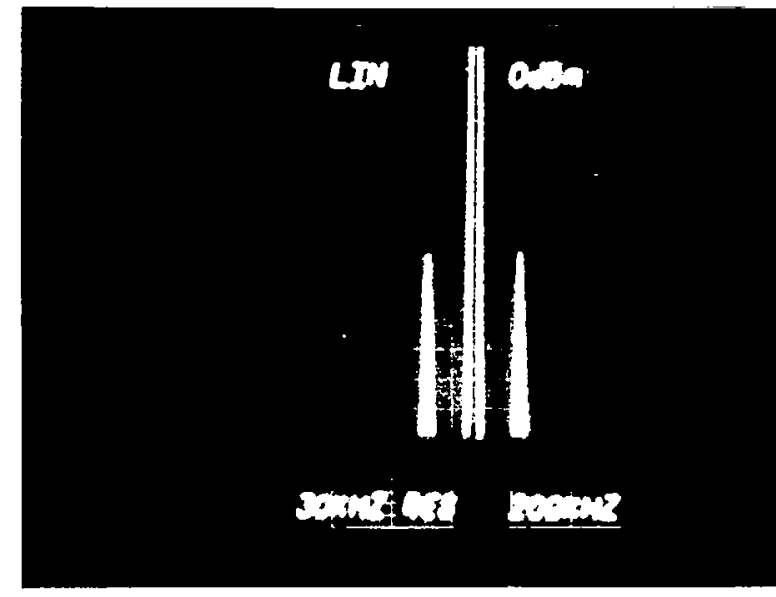

a. At $494 \mathrm{~N}$

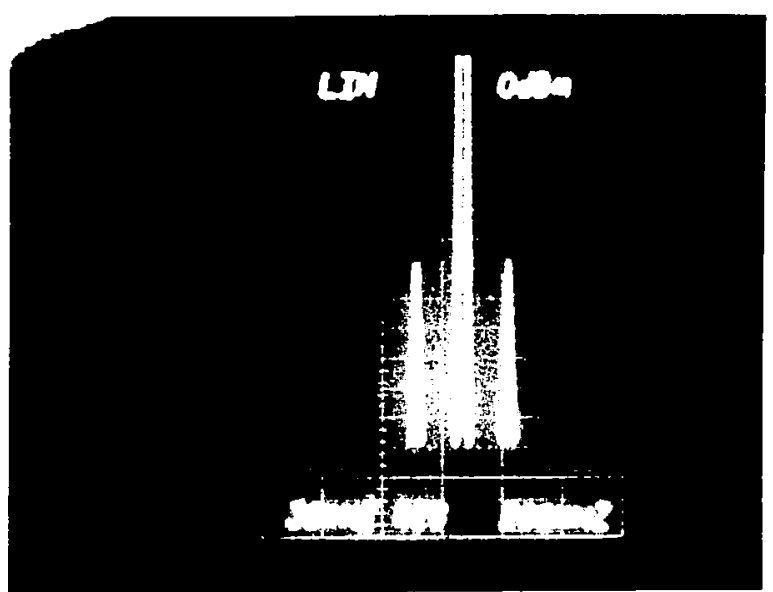

b. At $3587 \mathrm{~A}$

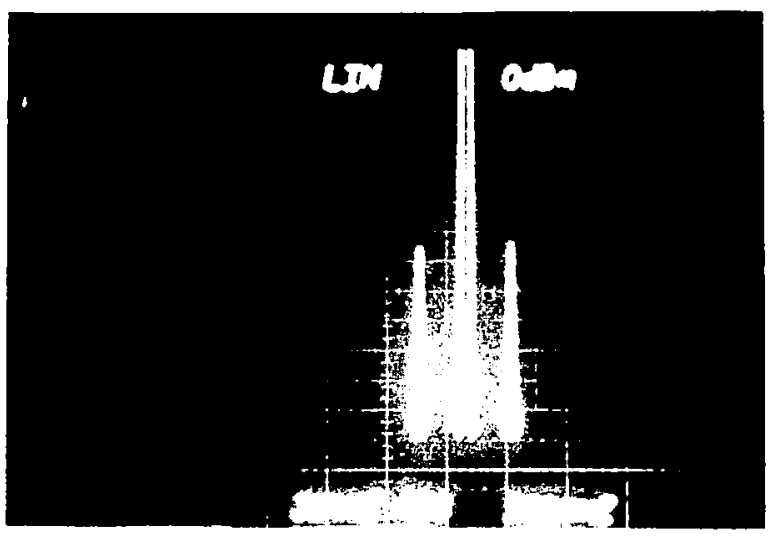

c. At $6786 \mathrm{~N}$

FIG. 12 - ULTRASONIC PULSE ATTENUATION VERSUS LOAD Of The $750 \mathrm{KHZ}$ in the Frequency Domain 


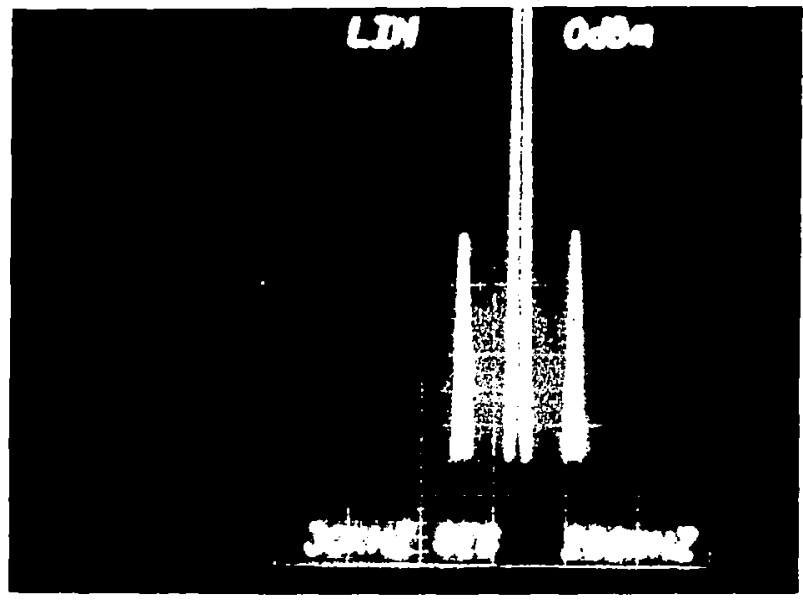

d. At $3565 \mathrm{~N}$

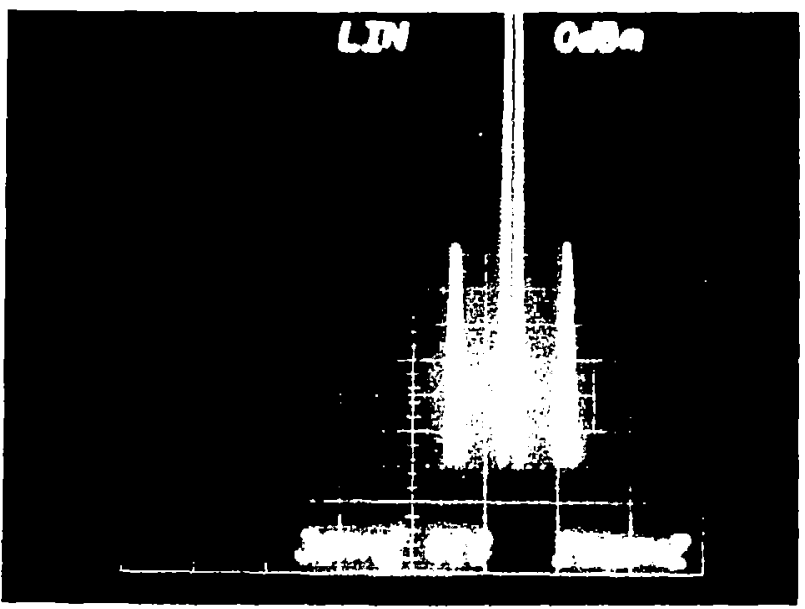

e. At $507 \mathrm{~N}$

FIG. 12 - ULTRASONIC PULSE ATTENUATION VERSUS LOAD of the $150 \mathrm{KHZ}$ in the Frequency Domain 


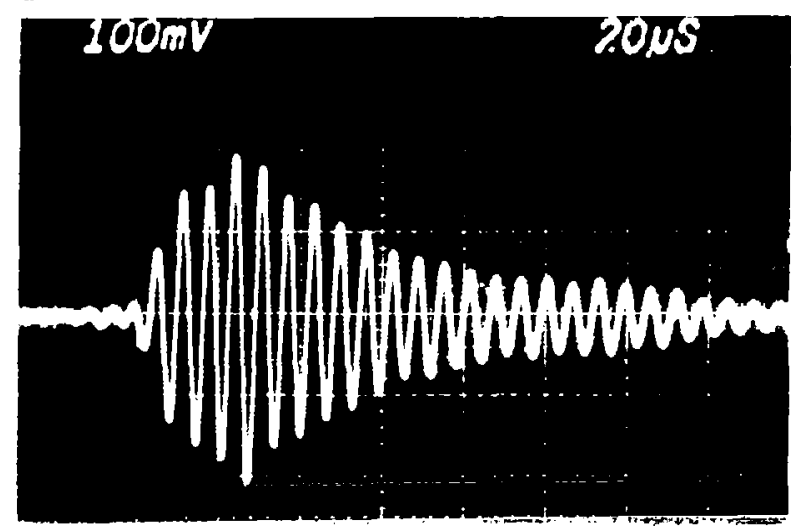

a. At $494 \mathrm{~N}$

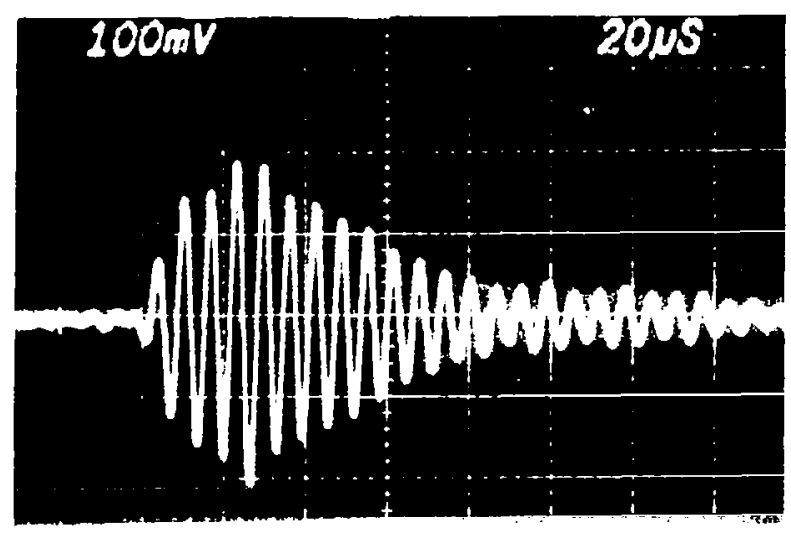

b. At $3587 \mathrm{~N}$

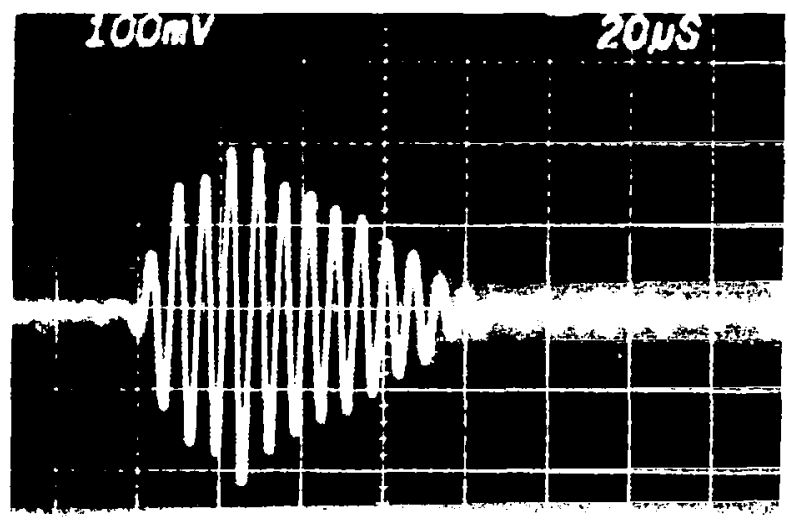

c. At $6786 \mathrm{~N}$

FIG. 13 - ULTRASONIC PULSE ATTENUATION VERSUS LOAD of the $150 \mathrm{KHZ}$ in the Time Domain 


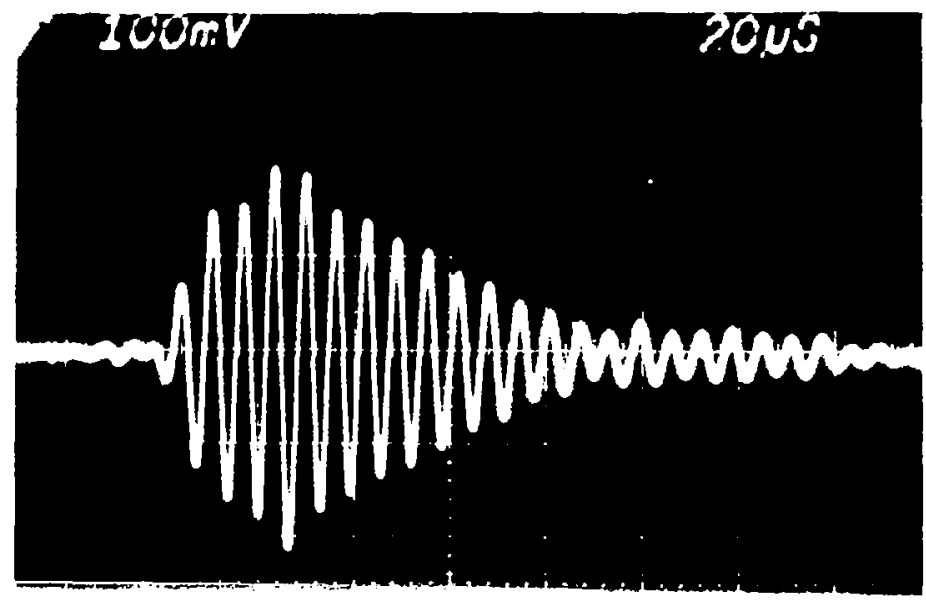

d. At $3565 \mathrm{~N}$

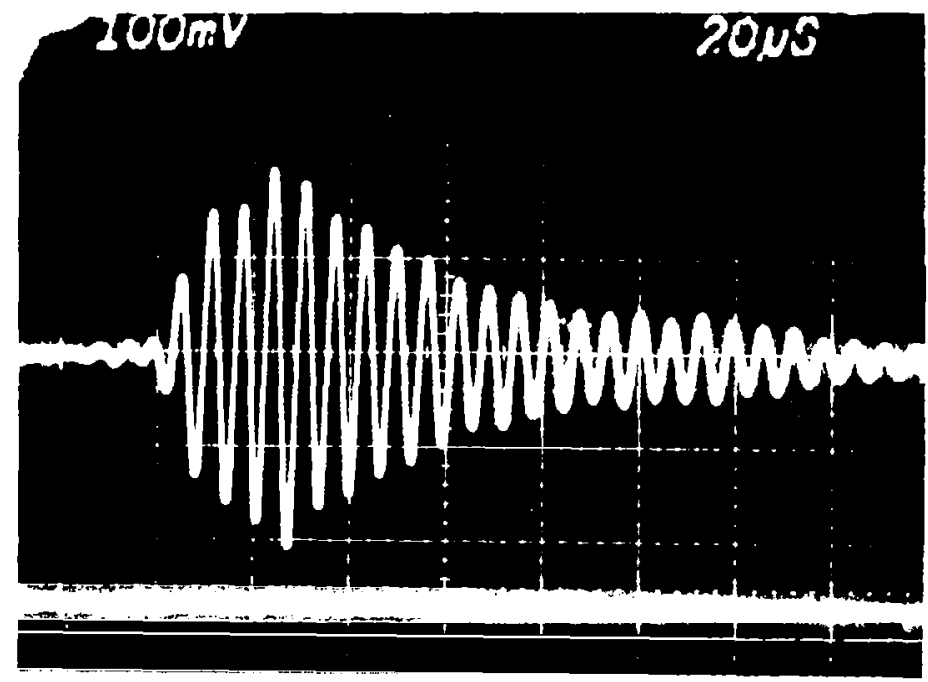

e. At $507 \mathrm{~N}$

FIG. 13 - ULTRASONIC PULSE ATTENUATION VERSUS LOAD OF $150 \mathrm{KHZ}$ in the Time Domain 
TABLE VII - BEHAVIOR OF THE 1.7 MHZ SPIKES IN THE TIME DOMAIN THE SPIKE NUMBER

\begin{tabular}{|c|c|c|c|c|}
\hline & $\underset{\%}{21 s t}$ & $\underset{\%}{22 n d}$ & $\underset{\%}{23 r d}$ & $\begin{array}{c}24 \text { th } \\
\%\end{array}$ \\
\hline 445 & 0.00 & +70.71 & +35.29 & +20.00 \\
\hline 3560 & -17.24 & -10.71 & +5.88 & -13.33 \\
\hline 6675 & -27.59 & -28.57 & -11.76 & -40.00 \\
\hline 3560 & -13.59 & -10.71 & +17.65 & -13.33 \\
\hline 445 & +6.90 & +10.71 & +64.71 & +53.33 \\
\hline
\end{tabular}

TABLE VIII-BEHAVIOR OF THE 1.9 MHZ SPIKES IN THE TIME DOMAIN THE SPIKE NUMBER

\begin{tabular}{|c|c|c|c|c|c|c|c|}
\hline & ${ }_{\%}^{8 \text { th }}$ & $\underset{\%}{9 \text { th }}$ & $\begin{array}{c}10 \text { th } \\
\%\end{array}$ & $\prod_{\%}^{17}$ th & $\underset{\%}{12 \operatorname{th}}$ & ${ }_{\%}^{13 \text { th }}$ & $\begin{array}{c}14 t \\
\%\end{array}$ \\
\hline 445 & -25.64 & 17.39 & 11.11 & 5.88 & 2.60 & 3.64 & 4.6 \\
\hline 3560 & -12.82 & 26.09 & 27.78 & 17.65 & 14.29 & 21.82 & 23.2 \\
\hline 6675 & +2.56 & 43.48 & 27.94 & 27.94 & 19.48 & 30.91 & 41.8 \\
\hline 3560 & -10.26 & 30.43 & 22.06 & 15.58 & 15.58 & 25.45 & 27.9 \\
\hline 445 & -30.77 & 17.39 & 11.76 & 7.79 & 7.79 & 12.73 & 16.2 \\
\hline
\end{tabular}




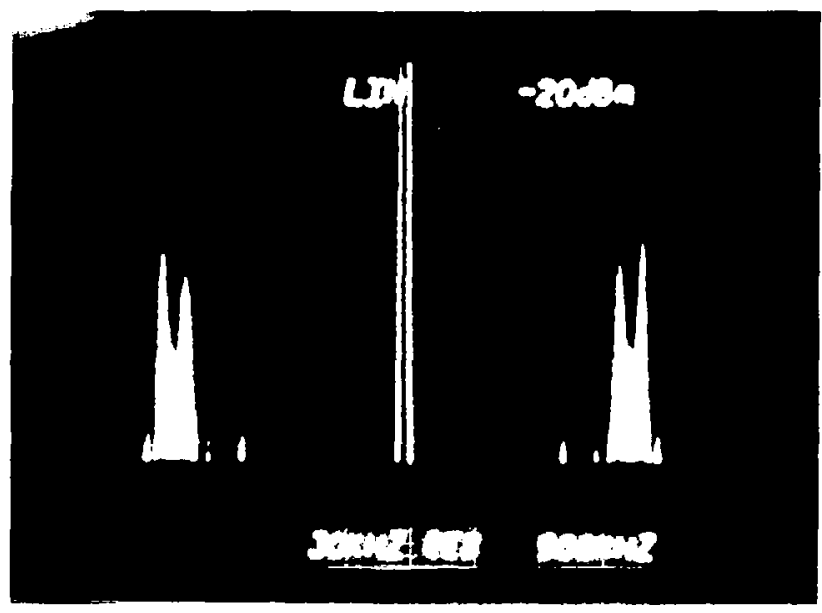

a. At $445 \mathrm{~N}$

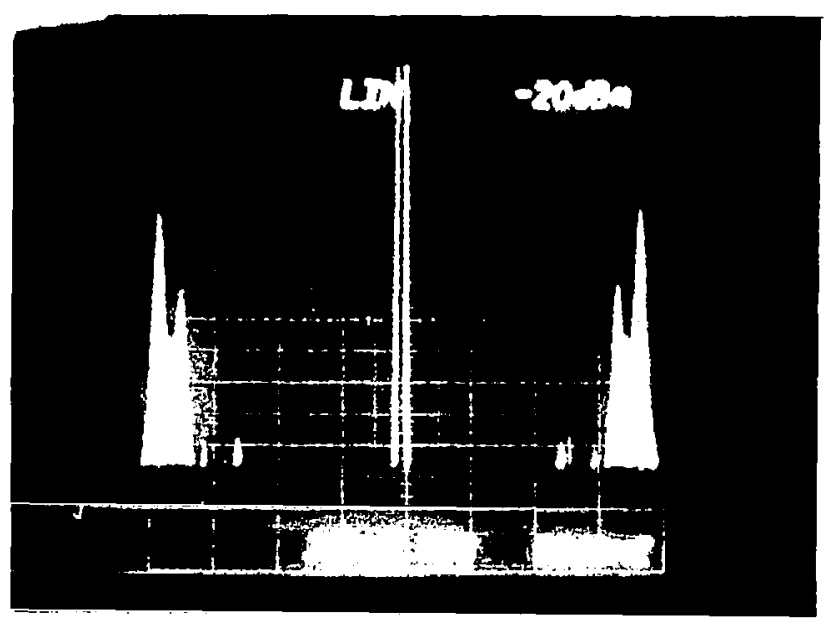

b. At $3560 \mathrm{~N}$

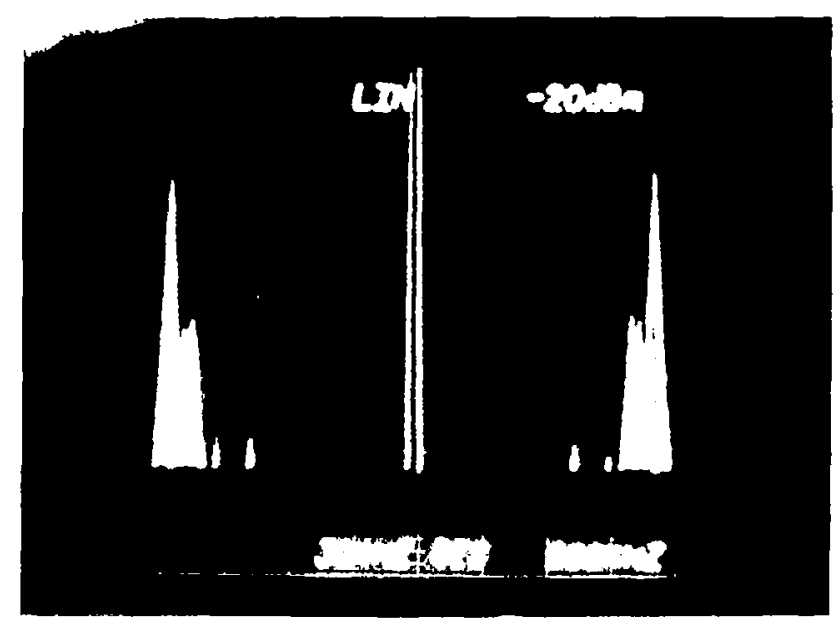

c. At $6675 \mathrm{~N}$

FIG. 14 - ULTRASONIC PULSE ATTENUATION VERSUS LOAD of the 1.7 and $1.9 \mathrm{MHZ}$ in the Frequency Domain 


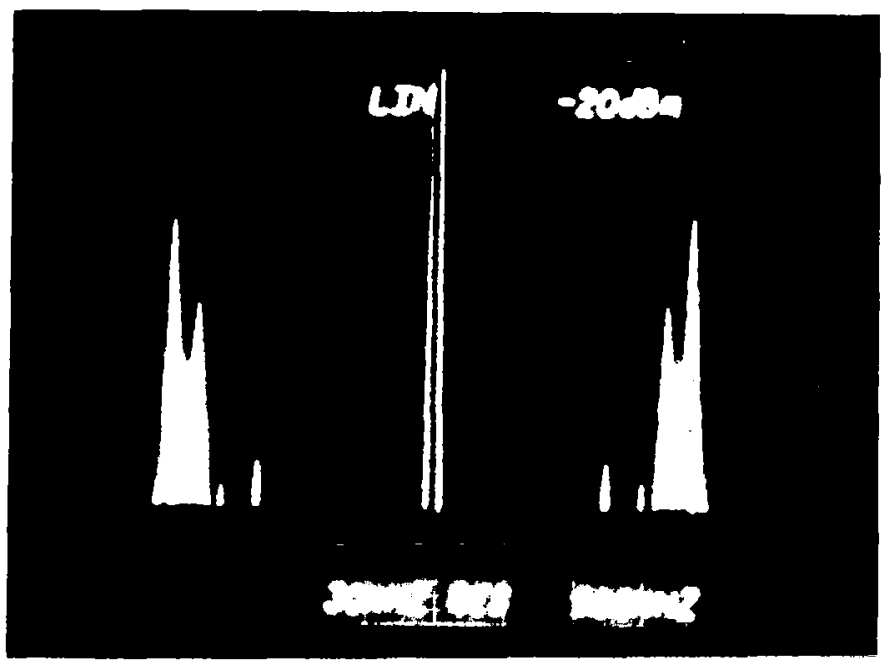

d. At $3560 \mathrm{~N}$

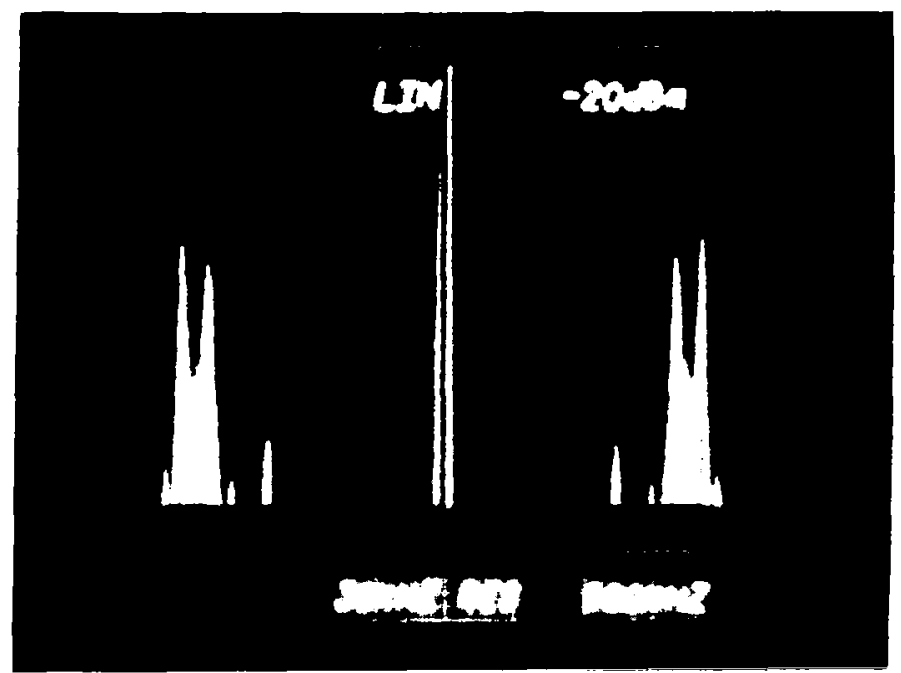

e. At $445 \mathrm{~N}$

FIG. 14 - ULTRASONIC PULSE ATTENUATION VERSUS LOAD of the 1.7 and $1.9 \mathrm{MHZ}$ in the Frequency Domain 


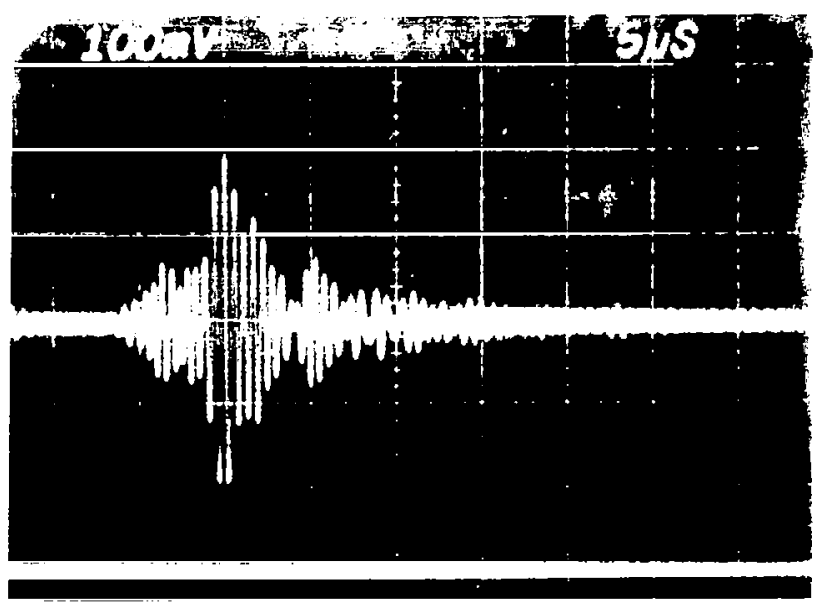

a. At $445 \mathrm{~N}$

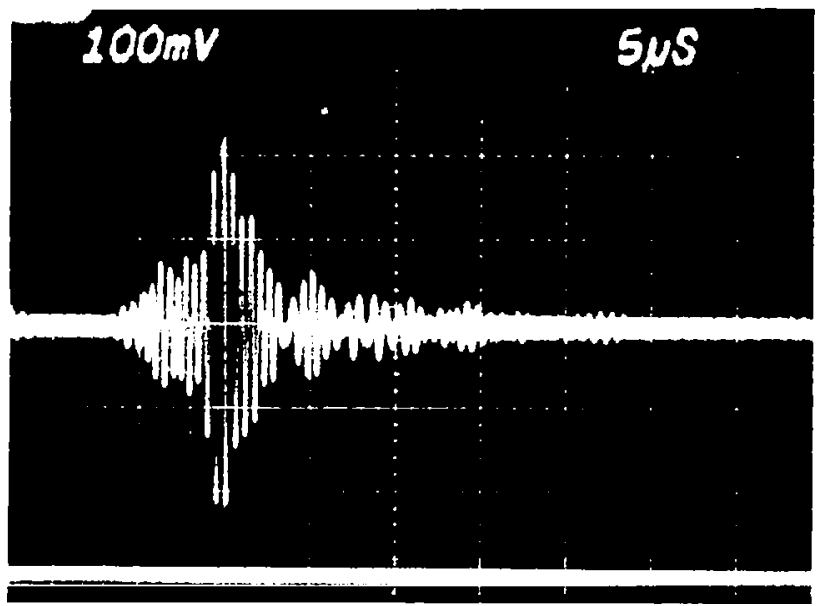

b. At $3560 \mathrm{~N}$

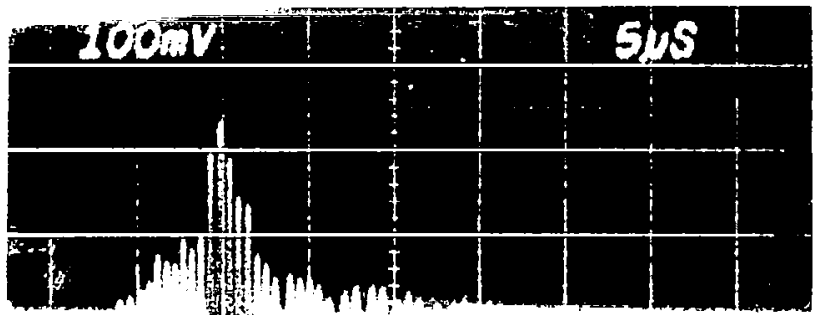

c. At $6675 \mathrm{~N}$

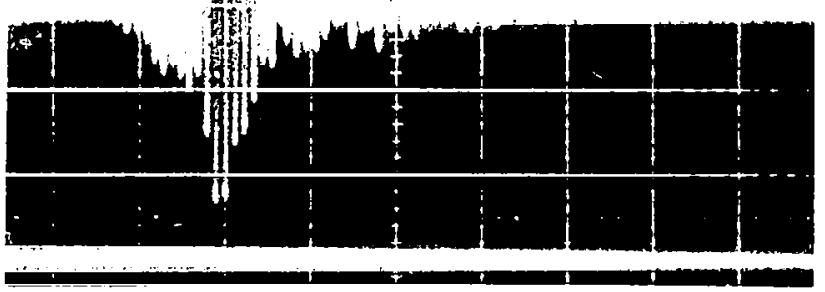

FIG. 15 - ULTRASONIC PULSE ATTENUATION VERSUS LOAD of the 1.7 and 1.9 $M H Z$ in the Time Domain 


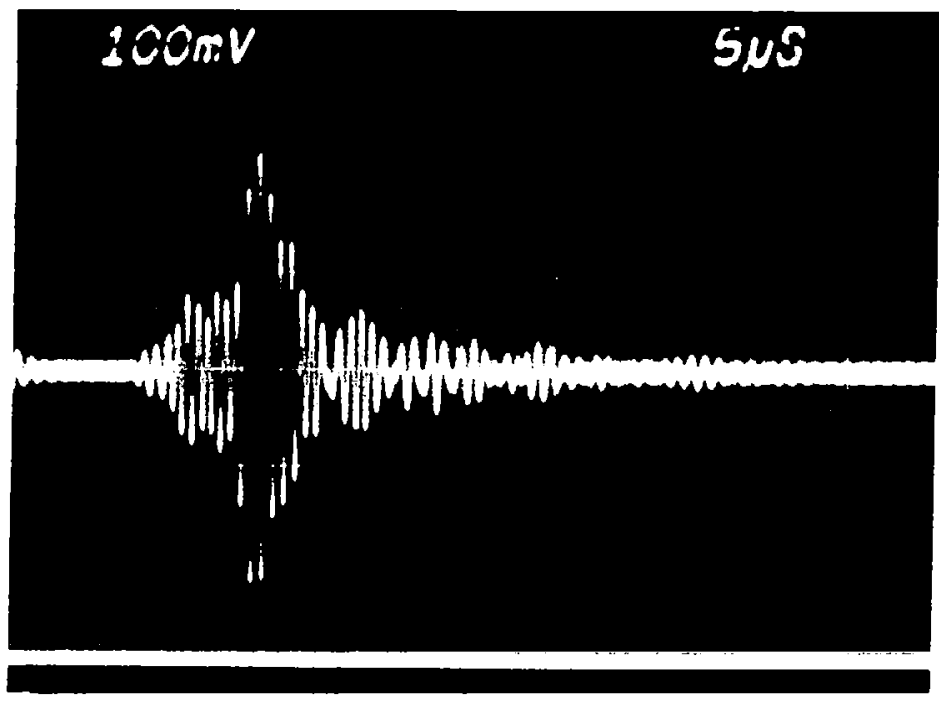

d. At 3560N

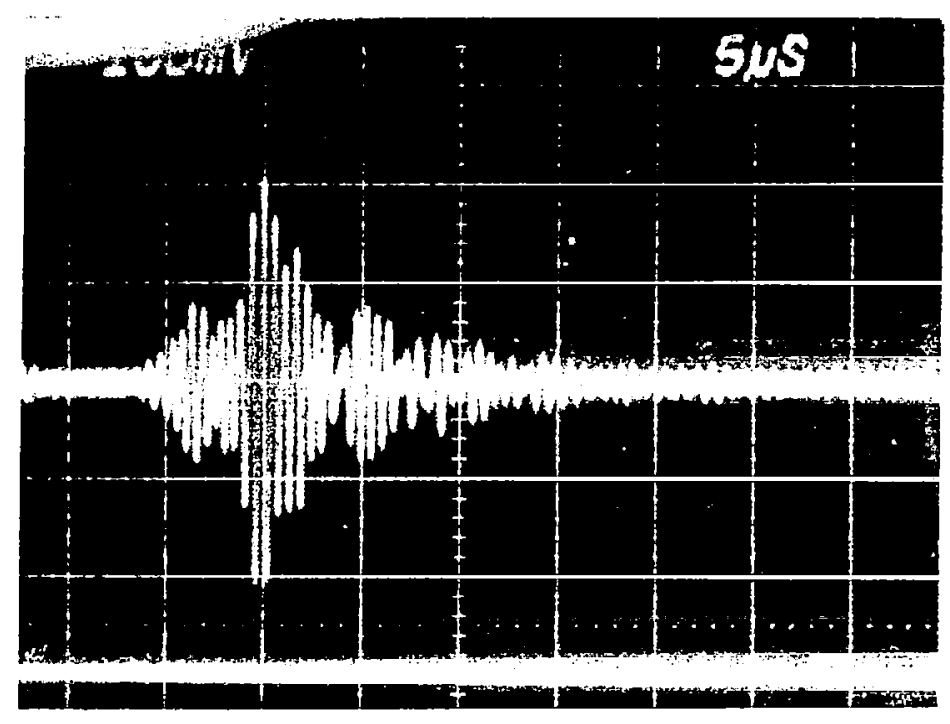

e. At $445 \mathrm{~N}$

FIG. 15 - ULTRASONIC PULSE ATTENUATION VERSUS LOAD of the 1.7 and 1.9 MHZ in the Time Domain 


\subsubsection{SUPERPOSITION OF DIFFERENT MODES}

Even when spectro-analysis results indicated a very narrow band of frequencies in the output signal, the time analysis on an individual spike base indicated the presence of different modes: Some spikes were behaving exactly as the single spike in the frequency domain, some others were behaving differently and in the rest of the spikes no definite behavior was observed. And as mentioned previously in Section 2.1, 1amb waves may exist in multimode states at a given frequency. For better understanding of what was said previously in this section one could follow the behavior of some spikes in Figure 5 and compare it to the result in Figure 10 or Figure 11.

\subsection{WAVE SPEEDS ARE WEAKLY DEPENDENT ON TENSILE LOAD}

From the data collected, the time shift for the first early spikes was measured at each load having $445 \mathrm{~N}$ as our reference load. Thereafter a percent of change in wave speed was calculated and is presented in Table $X$ below.

TABLE IX - PERCENT OF CHANGE IN WAVE SPEED

$\begin{array}{llccc}\text { F } & & & \text { LOAD,N } & \\ \text { R } & & 445 & 3560 & 6675 \\ \text { E } & 150000 & 0 & 1.87 & 3.20 \\ Q & 150 & 1.03 & 1.77 \\ \text { E } & 180000 & 0 & .72 & .84 \\ \text { N } & 250000 & 0 & 1.02 & 1.43 \\ C & 0 & 1.70 & 3.40 \\ \text { Y } & 850000 & 0 & & \end{array}$

When tensile loads were applied the distance between the two transducers increased and data showed that the corresponding delay time got smaller in 
Table IX. The phenomenon described cannot be explained at this time using linear theory.

\section{$3.4 \quad$ REPRODUCIBILITY}

Reproducibility means repeatability of the changes that were observed and their stability when cycling was occurring. As was mentioned earlier only two formal experiments for each frequency were recorded. In all experiments except for the $150 \mathrm{KHZ}$ experiment, repeatability was achieved after the cycling process had stabilized. As an example the $180 \mathrm{KHZ}$ first experiment is presented in Figure 16 and Figure 17, and the second experiment in Figure 18 and Figure 19, where one could observe and follow the changes in both experiments in both domains and perceive how well they agreed.

Reproduciblity of the signal itself was not a primary concern because of the experimental system limitations:

a - Coupling thickness was controlled only by the line pressure of the aluminum buffers

b - Riehle tensile machine could not be controlled with enough precision.

c - Distance between transducers as well as placing those transducers on the specimen did cause differences in the output signal itself.

Even though limitations existed, good case was taken to reproduce almost the same signal as presented in Figure 17 and Figure 19. 


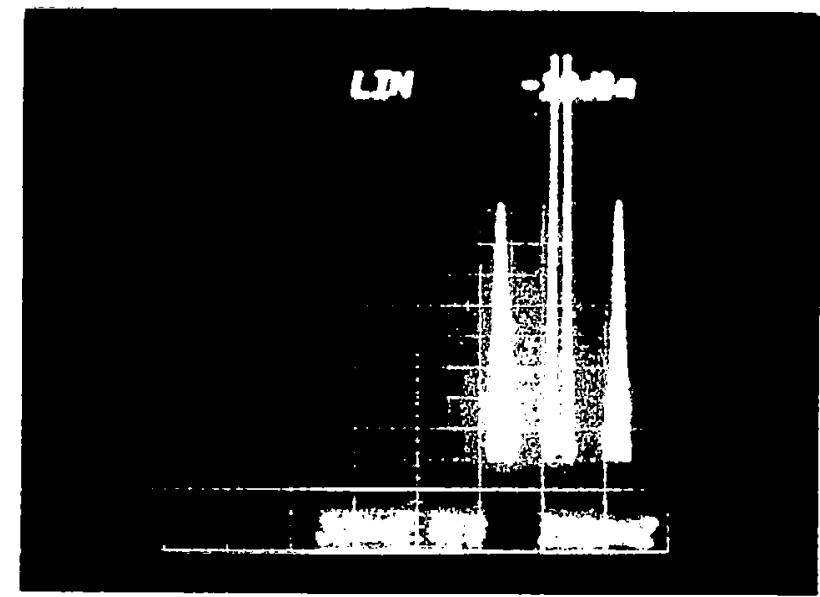

a. At $458 \mathrm{~N}$

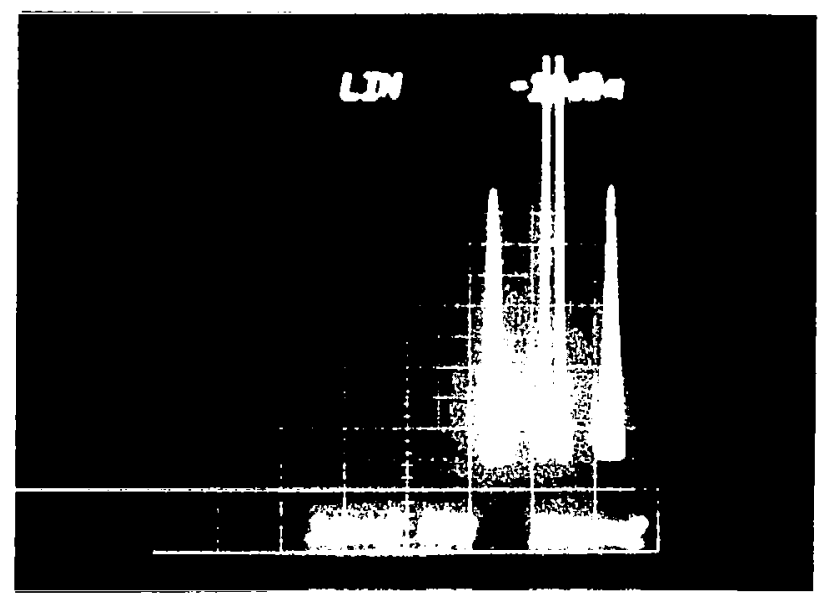

b. At $3630 \mathrm{~N}$

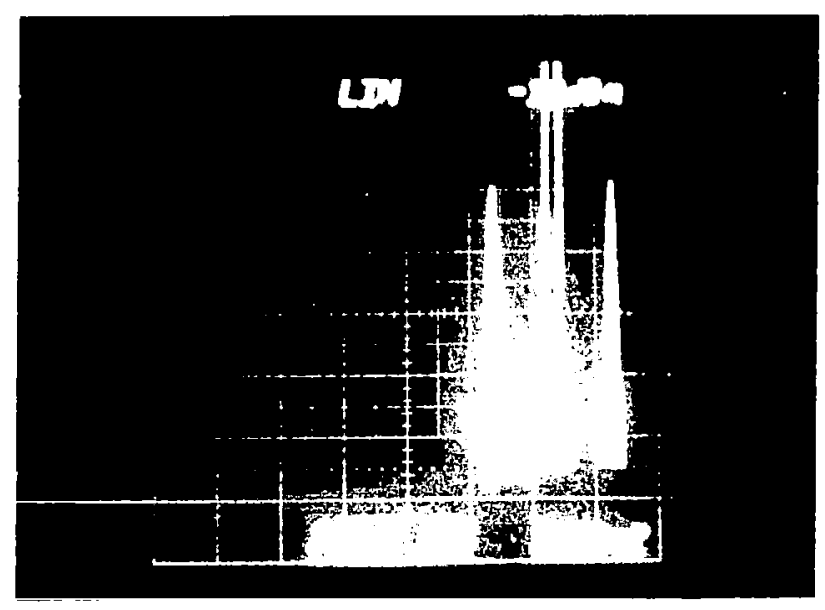

c. At $6786 \mathrm{~N}$

FIG. 16 - ULTRASONIC PULSE ATTENUATION VERSUS LOAD of the $180 \mathrm{KHZ}$ in the Frequency Domain 


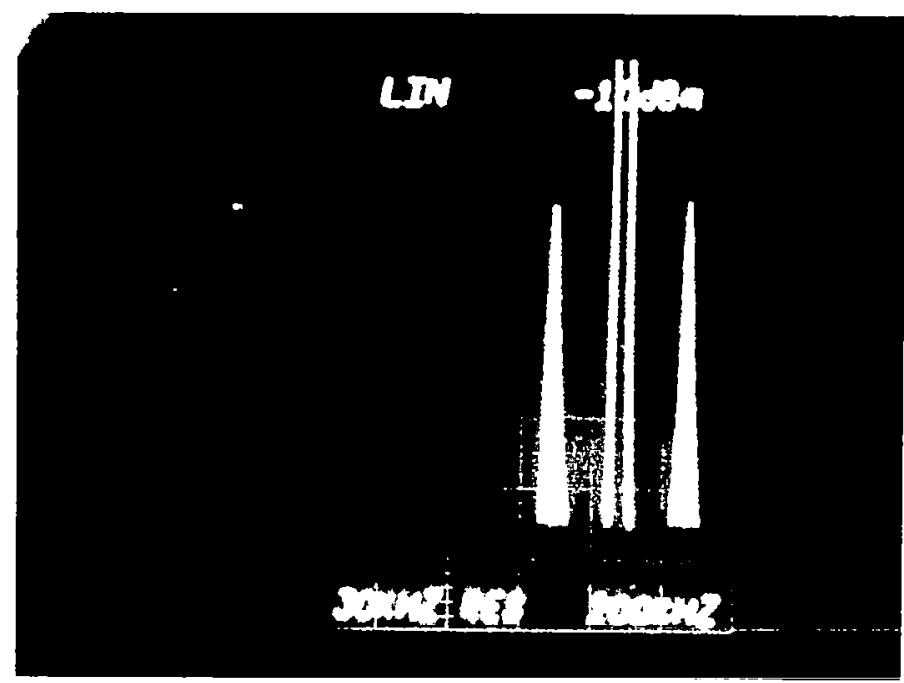

d. At $3573 \mathrm{~N}$

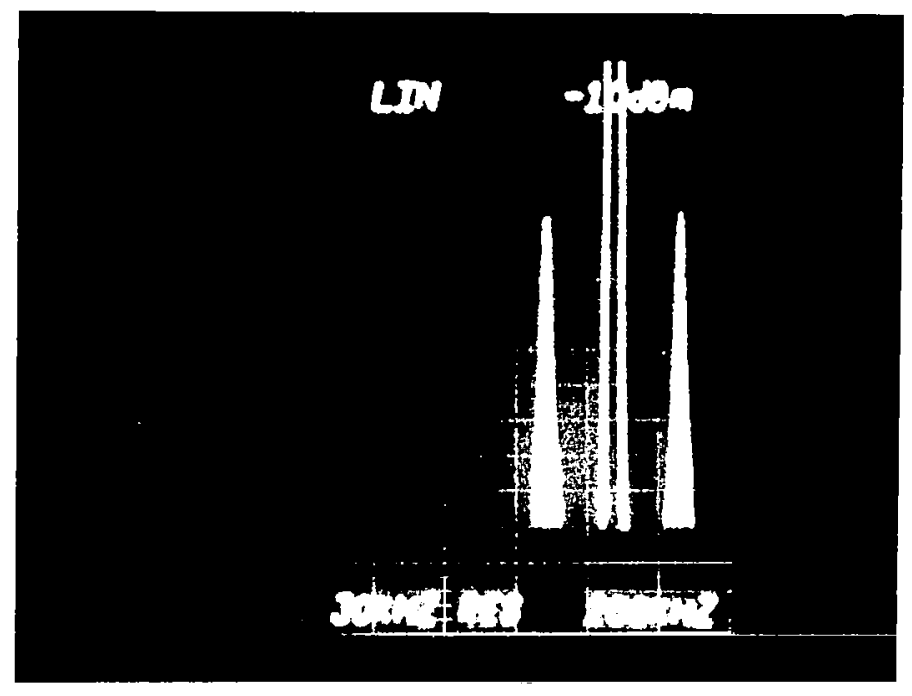

e. At $490 \mathrm{~N}$

FIG. 16 - ULTRASONIC PULSE ATTENUATION VERSUS LOAD of $180 \mathrm{KHZ}$ in the Frequency Domain 


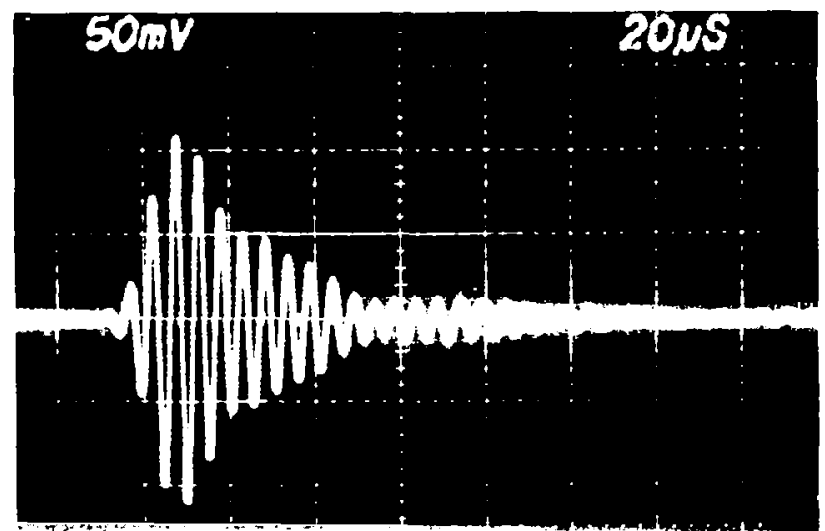

a. At $458 \mathrm{~N}$

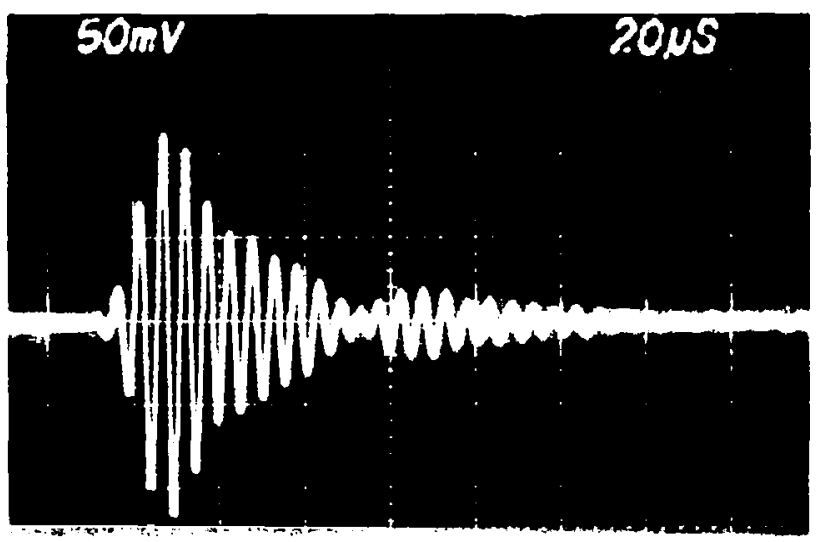

b. At $3630 \mathrm{~N}$

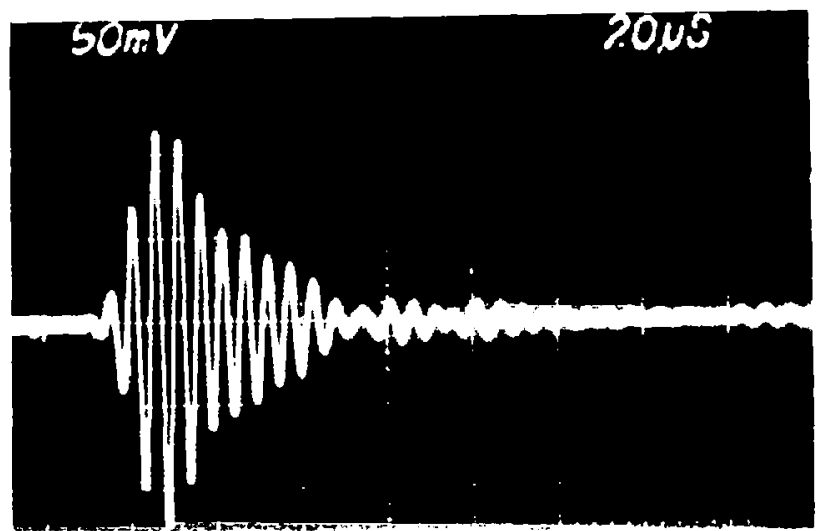

c. At $6786 \mathrm{~N}$

FIG. 17 - ULTRASONIC PULSE ATTENUATION VERSUS LOAD of the $180 \mathrm{kHz}$ in the Time Domain 


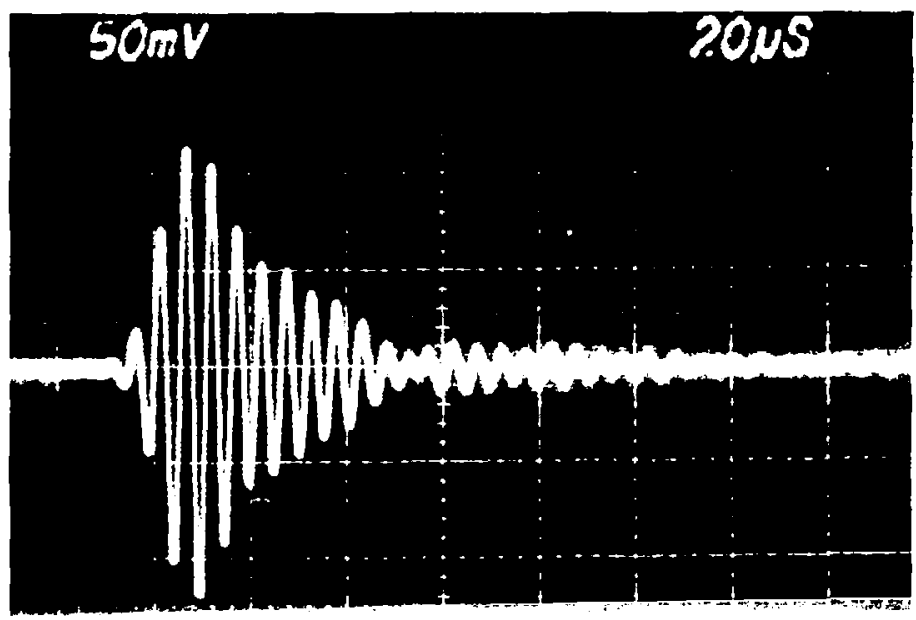

d. At $3573 \mathrm{~N}$

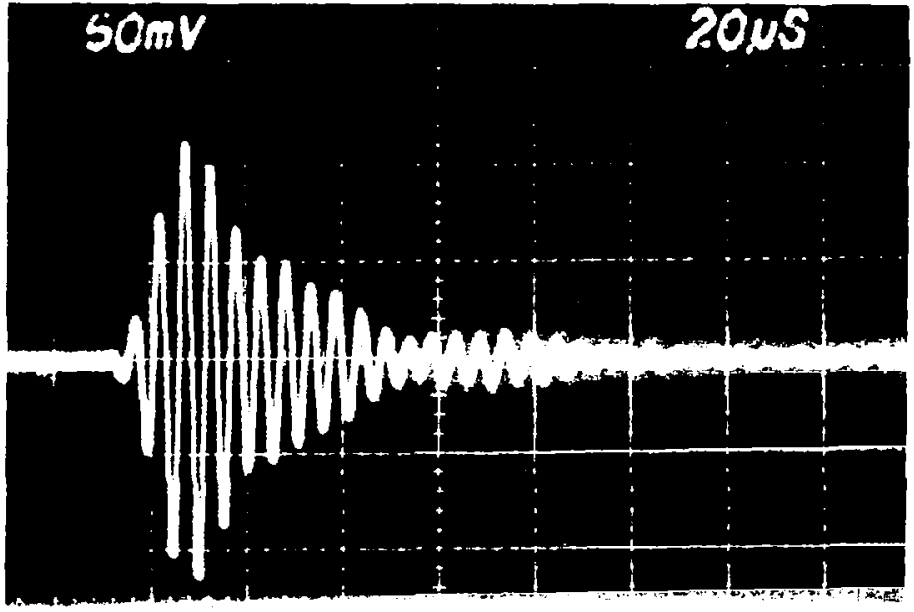

e. At $490 \mathrm{~N}$

FIG. 17 - ULTRASONIC PULSE ATTENUATION VERSUS LOAD of $180 \mathrm{KHZ}$ in the Time Domain 

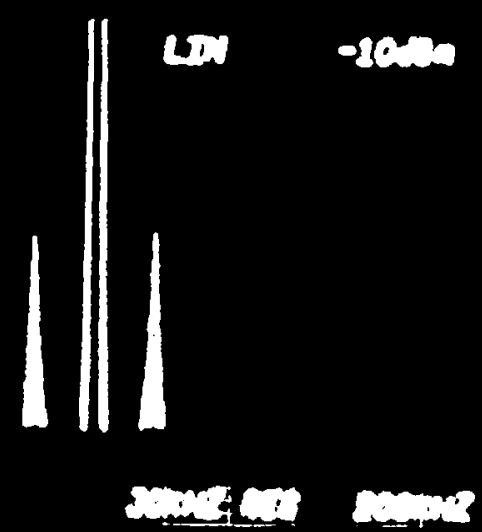

a. At $507 \mathrm{~N}$

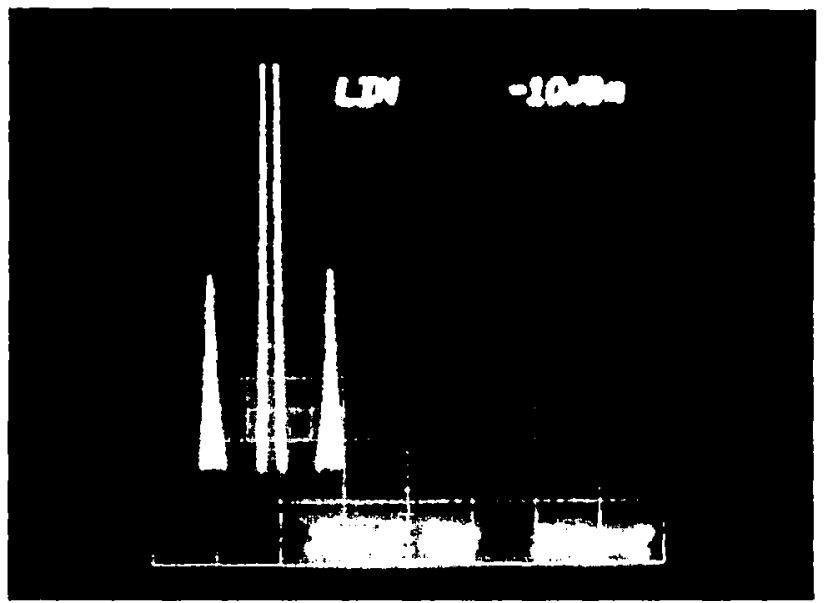

b. At $3631 \mathrm{~N}$

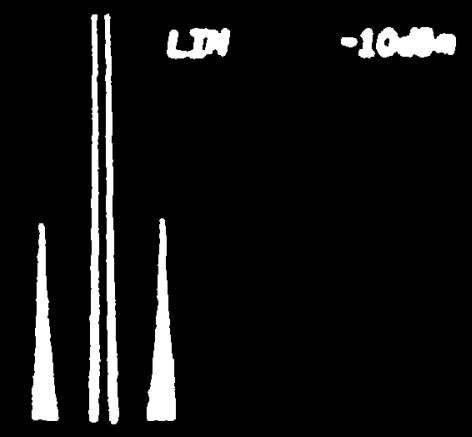

c. At $6888 \mathrm{~N}$

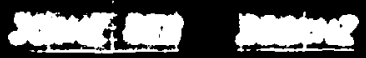

FIG. 18 - ULTRASONIC PULSE ATTENUATION VERSUS LOAD of the $180 \mathrm{KHZ}$ in the Frequency Domain 


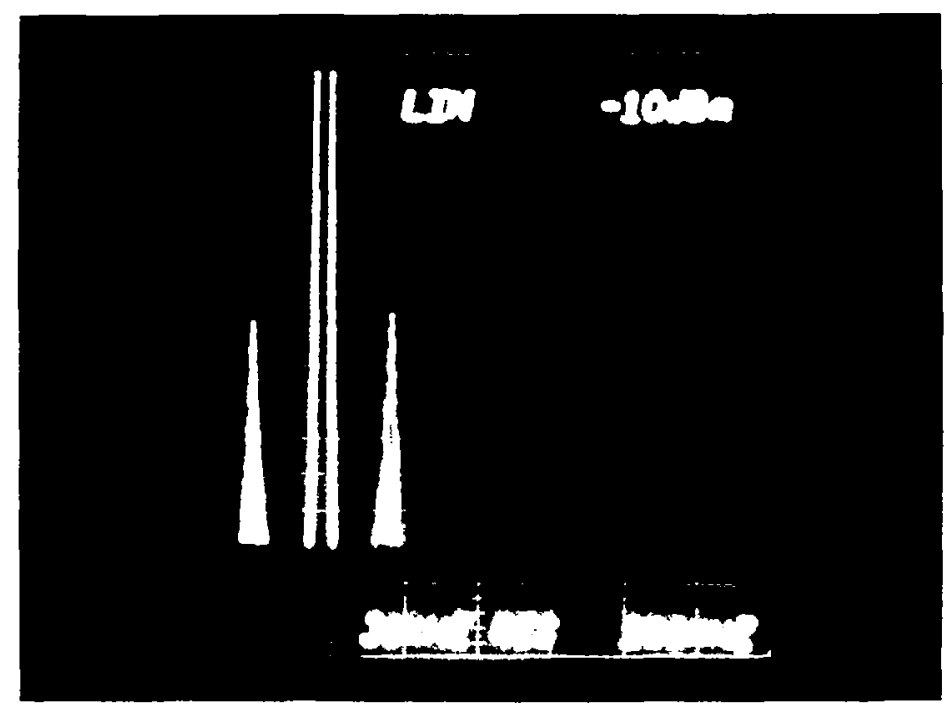

d. At $3582 \mathrm{~N}$

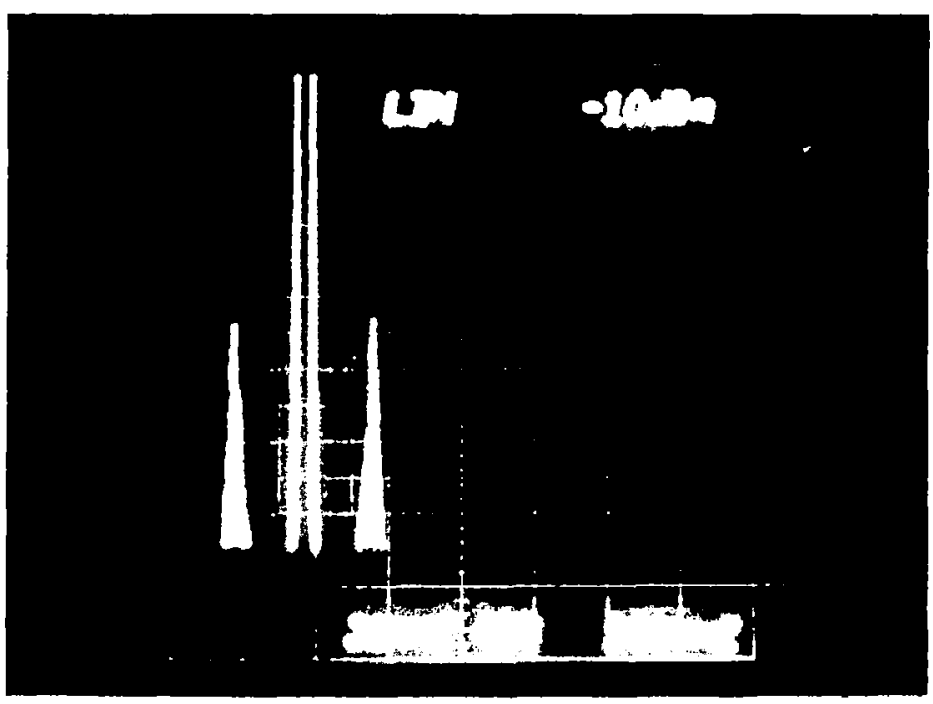

e. At $556 \mathrm{~N}$

FIG. 18 - ULTRASONIC PULSE ATTENUATION VERSUS LOAD of $180 \mathrm{KHZ}$ in the Frequency Doma in 


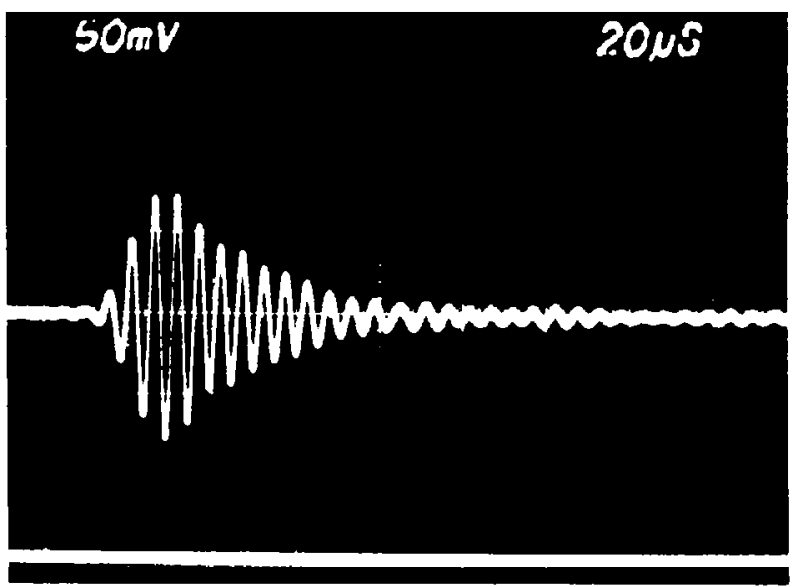

a. At $507 \mathrm{~N}$

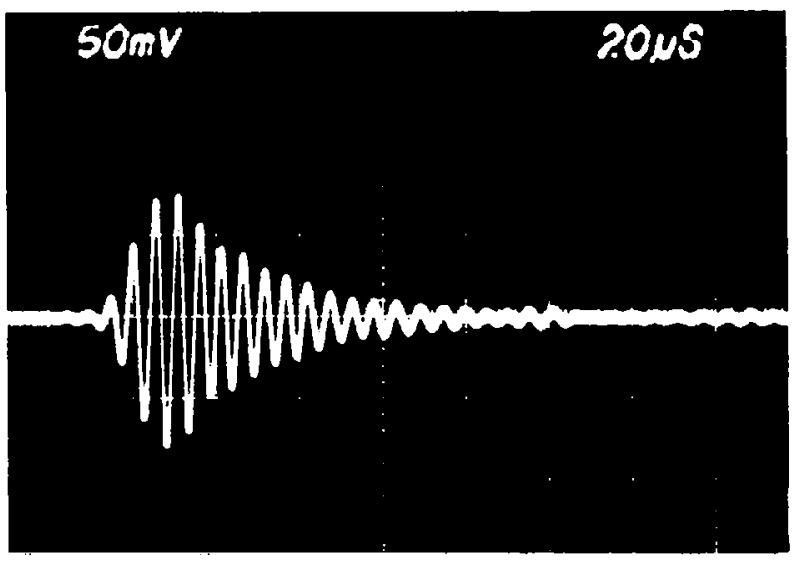

b. At $3631 \mathrm{~N}$

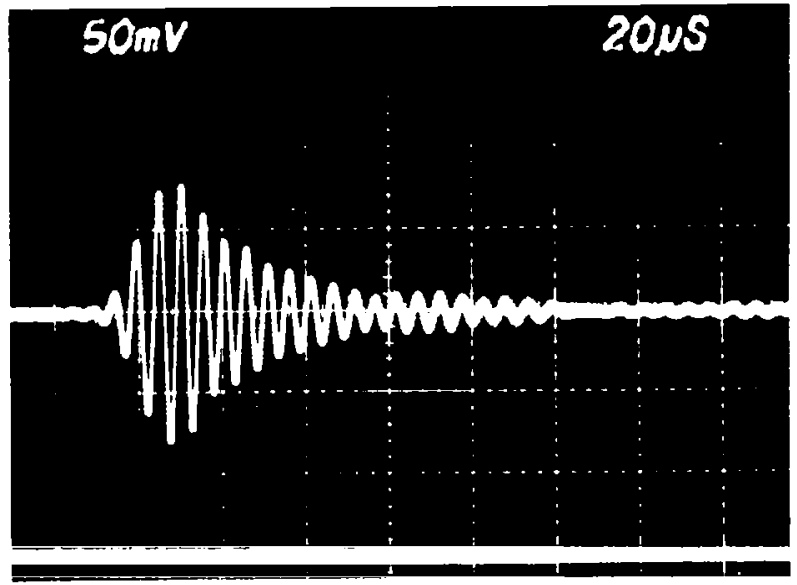

c. At $6888 \mathrm{~N}$

FIG. 19 - ULTRASONIC PULSE ATTENUATION VERSUS LOAD of the $180 \mathrm{KHZ}$ in the Time Domain 


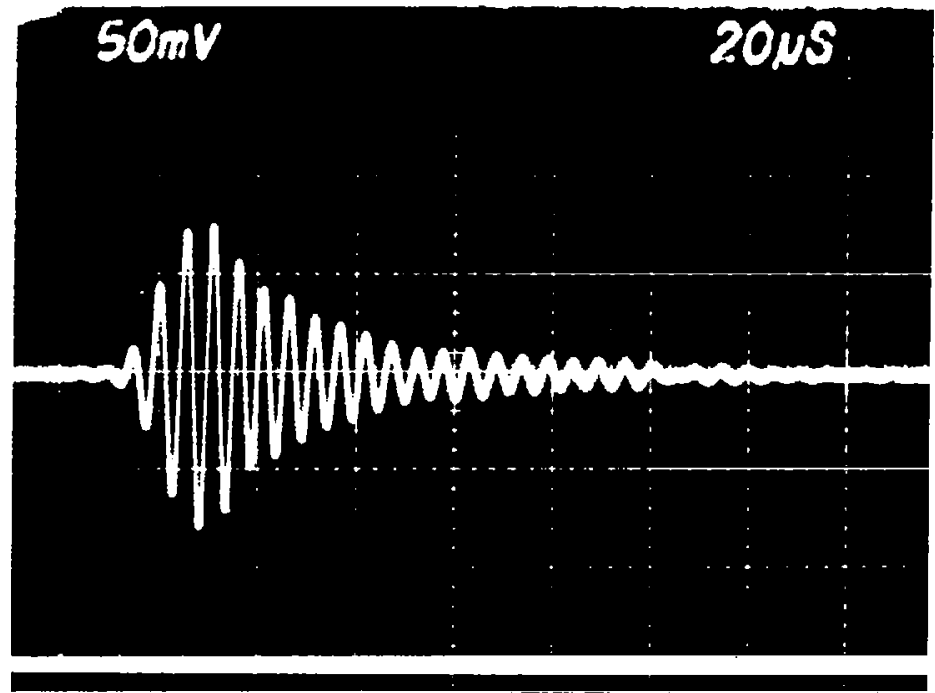

d. At $3582 \mathrm{~N}$

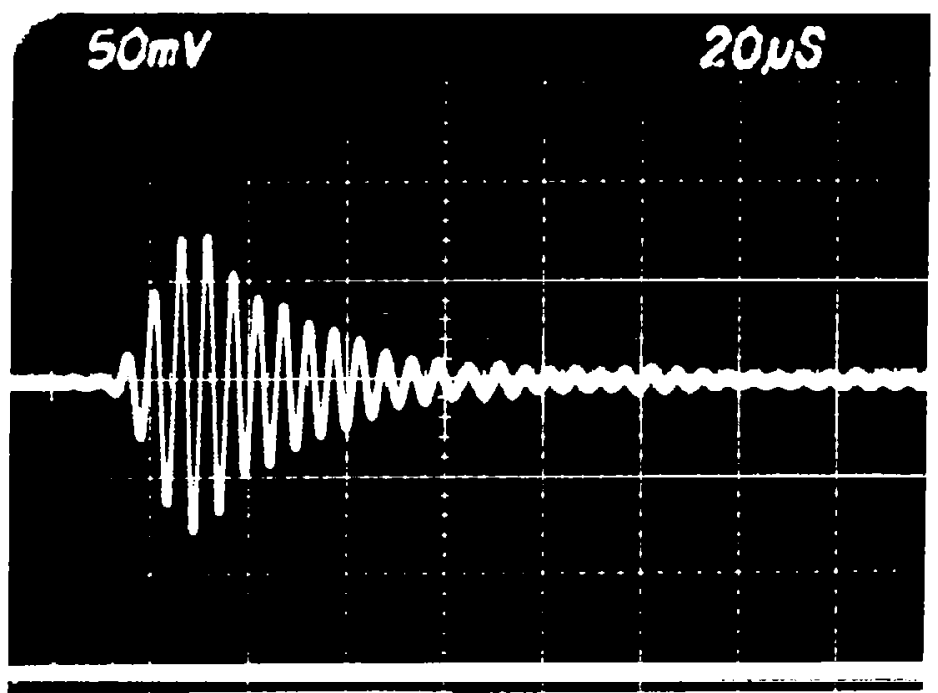

e. At $556 \mathrm{~N}$

FIG. 19 - ULTRASONIC PULSE ATTENUATION VERSUS LOAD of $180 \mathrm{KHZ}$ in the Time Domain 


\section{CHAPTER IV}

CONCLUSION

It has been shown that dispersion did occur, i.e., wave speeds were frequency dependent. Moreover, it was found that flexural/Lamb waves existed, and a superposition of different modes existed in the stress wave output of the signal.

It has been proven that attenuation depended strongly on tensile stress. Also it was observed that attenuation was frequency dependent.

Finally, it was demonstrated that wave speeds were weakly dependent on tensile load.

Further research is needed using a pulsing system producing narrow band frequencies since all effects measured were frequency dependent. 


\section{PART II}

LAMB WAVE PROPAGATION 


\section{CHAPTER 1}

\section{INTRODUCTION}

The research conducted here is devoted to gaining an understanding of the geometric dispersion mechanisms in fiber reinforced composite specimens. Geometric dispersion means that wave speeds are frequency dependent because of geometric constraints and not because of material properties. A short review of wave propagation in solids will be presented as an introduction to the research results.

The theory of elastic wave propagation in solids shows that two types of elastic waves may be propagated in an unbounded or extended isotropic medium - longitudinal waves where the particle motion is along the direction of propagation, and transverse waves where the particle motion is normal to the direction of propagation or parallel to the wave front. Each of these two wave types has its characteristic wave speed and is non dispersive.

In extended or unbounded anisotropic elastic materials three waves of different speeds may exist for wave propagation in an arbitrary direction. In general, the particle displacement has components along and normal to the direction of wave propagation for all three waves. These waves cannot be classified as longitudinal or transverse waves except in certain specified directions corresponding to axes of symmetry. The wave propagation is non dispersive in linear elastic anisotropic materials. Williams et.al. ${ }^{13}$ has shown that dispersion does not occur in the graphite-epoxy materials he tested. 
Elastic surface waves may exist where there is a bounding surface. This type of wave is created because the free boundary conditions must be satisfied. These surface waves travel without change in form; the particle motion is both vertical and horizontal with an elliptic trajectory. Moreover they are frequency independent or nondispersive. Lord Rayleigh ${ }^{16}$ has shown that their effect decreases rapidly with depth and that their velocity of propagation is smaller than that of transverse waves.

In an isotropic plate of small thickness the analysis of wave propagation becomes more complicated. Wave propagation in plates or waveguides produces what are called Lamb (or plate) waves which exhibit geometric dispersion. Once the waves start bouncing back and forth between the bounding surfaces it is very difficult to trace the actual reflections. The general direction of propagation is, however, parallel to the bounding surfaces. The analysis of harmonic wave propagation in wave guides leads to a dispersion mechanism with modes of wave propagation where wavelength to thickness ratio, phase velocity, and group velocity are important quantities.

When an incident longitudinal or transverse wave strikes a free surface two waves are generated on reflection, one is longitudinal, the other is shear wave. The interaction between longitudinal and shear waves in a relatively thin plate produces Lamb waves travelling parallel to the free surface. These waves in which the particle motion occurs both parallel to the wave propagation and perpendicular to the freesurface, are of two families of modes, symmetric and antisymmetric (see figure 20). The symmetric modes have particle motions which are symmetric with respect to the midplane, i.e. for $(x, y, z)$ and $(x, y,-z)$ the longitudinal displacements are equal, but the 


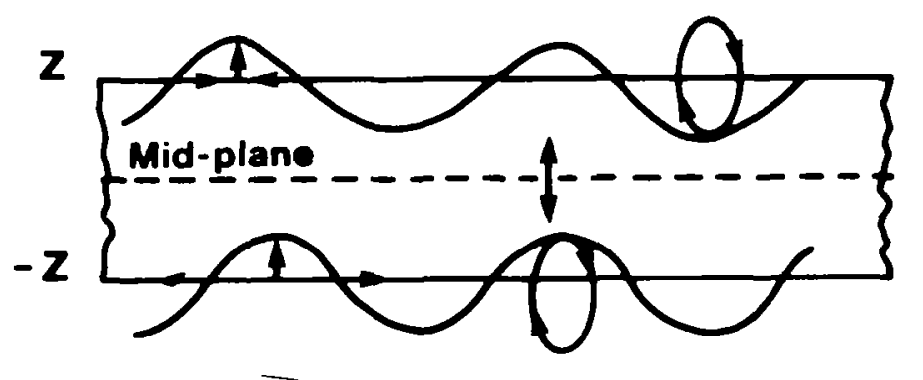

a. antisymmetrical lamb wave

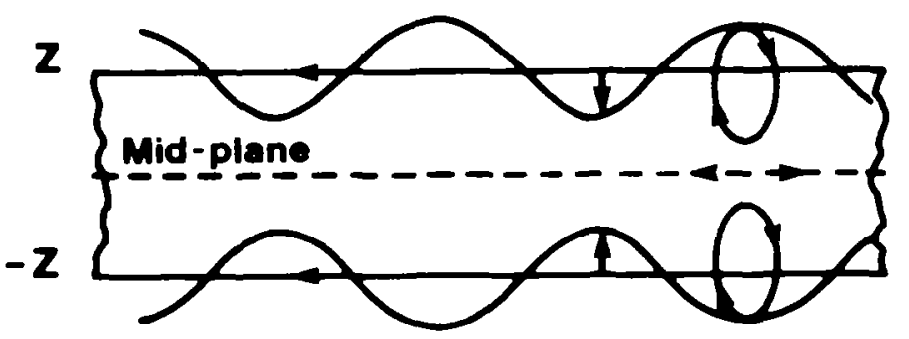

b. symmetrical

lamb wave

Fig. 20 Symmetrical and antisymmetrical lamb waves. $\leftrightarrow, \rightarrow, \bigcap$ particle motion 
transverse displacements are equal in magnitude and opposite in direction. The antisymmetric modes have particle motions which are antisymmetric with respect to the midplane, i.e. for $(x, y, z)$ and $(x, y,-z)$ the transverse displacements are equal in magnitude and opposite in direction. Infinite number of modes of propagation exist in a plate according to Horace Lamb ${ }^{17}$, this was confirmed experimentally by D. C. Worlton ${ }^{18}$ for aluminum and zirconium materials.

Rayleigh waves or Lamb waves may exist on the surface of a wave guide depending on the thickness of the wave guide and the frequency of excitation. As the product of frequency and thickness gets large, the boundary conditions, in effect, decouple and the Lamb waves become Rayleigh waves as shown in Figure 21. Meitzler ${ }^{19}$ has demonstrated experimentally that different modes of Lamb wave propagation exhibit different attenuation behavior because of the strong frequency and thickness dependencies.

Habeger, Mann, and Baum ${ }^{20}$ have studied Lamb wave propagation in paper, an orthotropic material. They have developed the dispersion curves for the symmetric and the antisymmetric cases. Their analysis may be applied directly to unidirectional fiber reinforced composites.

The review of literature on wave propagation in solids and the results presented in Part I of this report clearly demonstrate that wave propagation in thin plates is in the form of Lamb waves. The research reported in this part will present experimental evidence of Lamb wave propagation and related dispersion mechanisms in thin graphite-epoxy fiber reinforced composite specimens.

This research is a necessary prelude to further studies on attenuation and damage in thin plates or structures of fiber reinforced materials. 


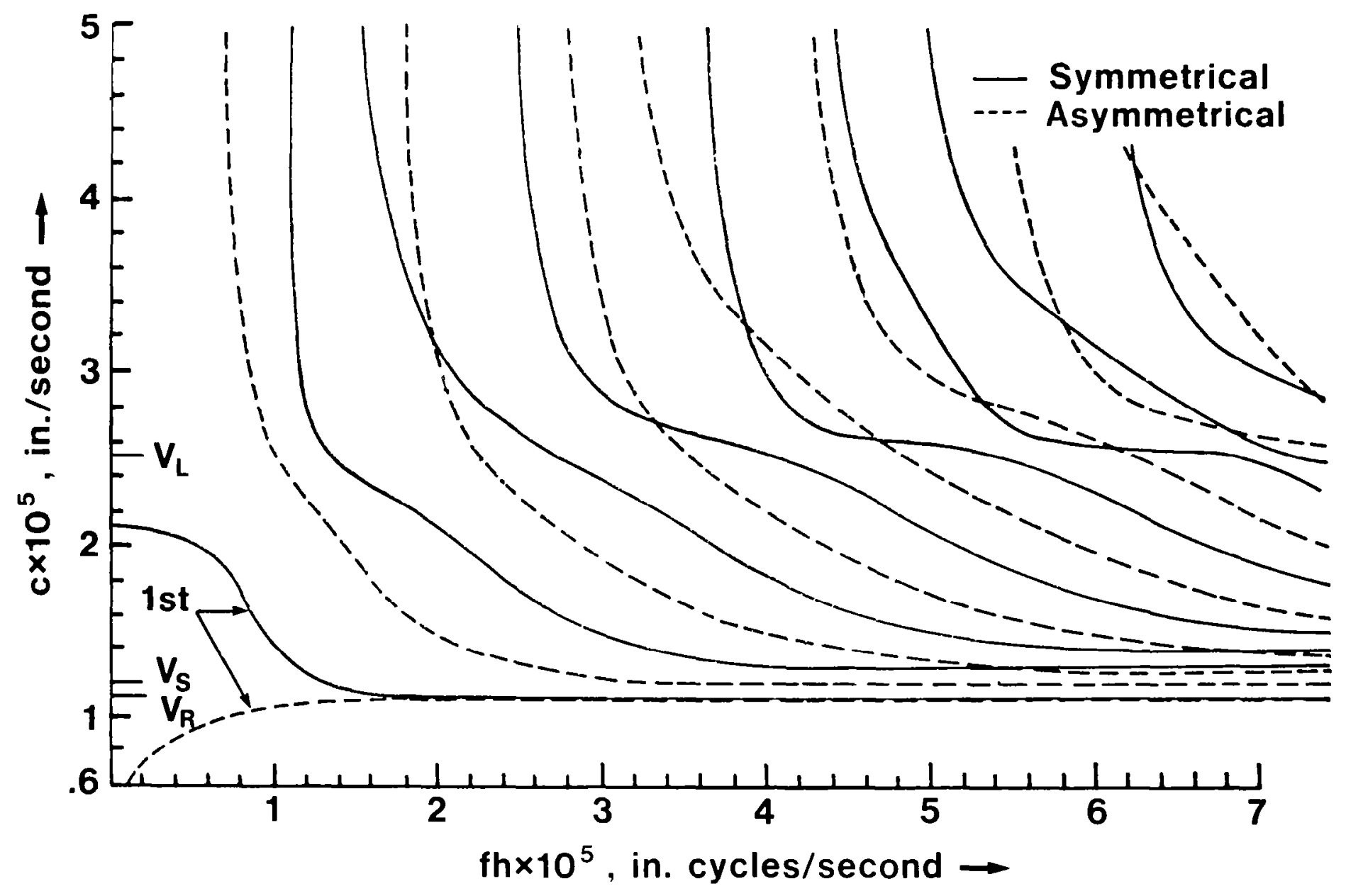

Fig. 21 LAMB WAVE MODES IN ALUMINUM (AFTER LAMB). 


\section{LAMB WAVE EXCITATION}

\subsection{TRANSDUCER/SPECIMEN TESTING CONFIGURATIONS}

Worlton $^{18}$, Victorov ${ }^{17}$, and Firestone ${ }^{21}$ have presented methods for exciting Lamb waves; the wedge method of inserting Lamb waves of specified phase velocities is most common and was adapted for this research.

Three transducer/specimen configurations were used for testing in this research (Figure 22). The configurations where $\theta=0^{\circ}$ and $\theta=90^{\circ}$ are widely used especially in the work of $\operatorname{Vary}^{7}$ and Williams ${ }^{13}$. Worlton ${ }^{18}$ varied $\theta$ between $0^{\circ}$ and $90^{\circ}$ as he studied Lamb waves in aluminum and zirconium plates. This very last configuration is used to generate and detect Lamb-wave modes at a specified angle of incidence. Detecting these modes depends not only on the angle of incidence but also on the frequency of the transmitted wave, on the material thickness, and on the material properties.

In all three configurations the wave will be propagating in the $x_{1}$ direction with the partical motion in both the $x_{1}$ and $x_{3}$ directions.

Panametric and Dunegan transducers were used in these experiments. Their properties are tabulated in Table II on page 6 of Part I.

Strain gauges were mounted on to the transducer holders to measure the pressure applied to the transducers. Williams, et.al. ${ }^{13}$ defined and measured a "saturation pressure" which is required for reproducible coupling of transducer to specimen; this pressure was monitored by the strain-gauged transducer holders. 


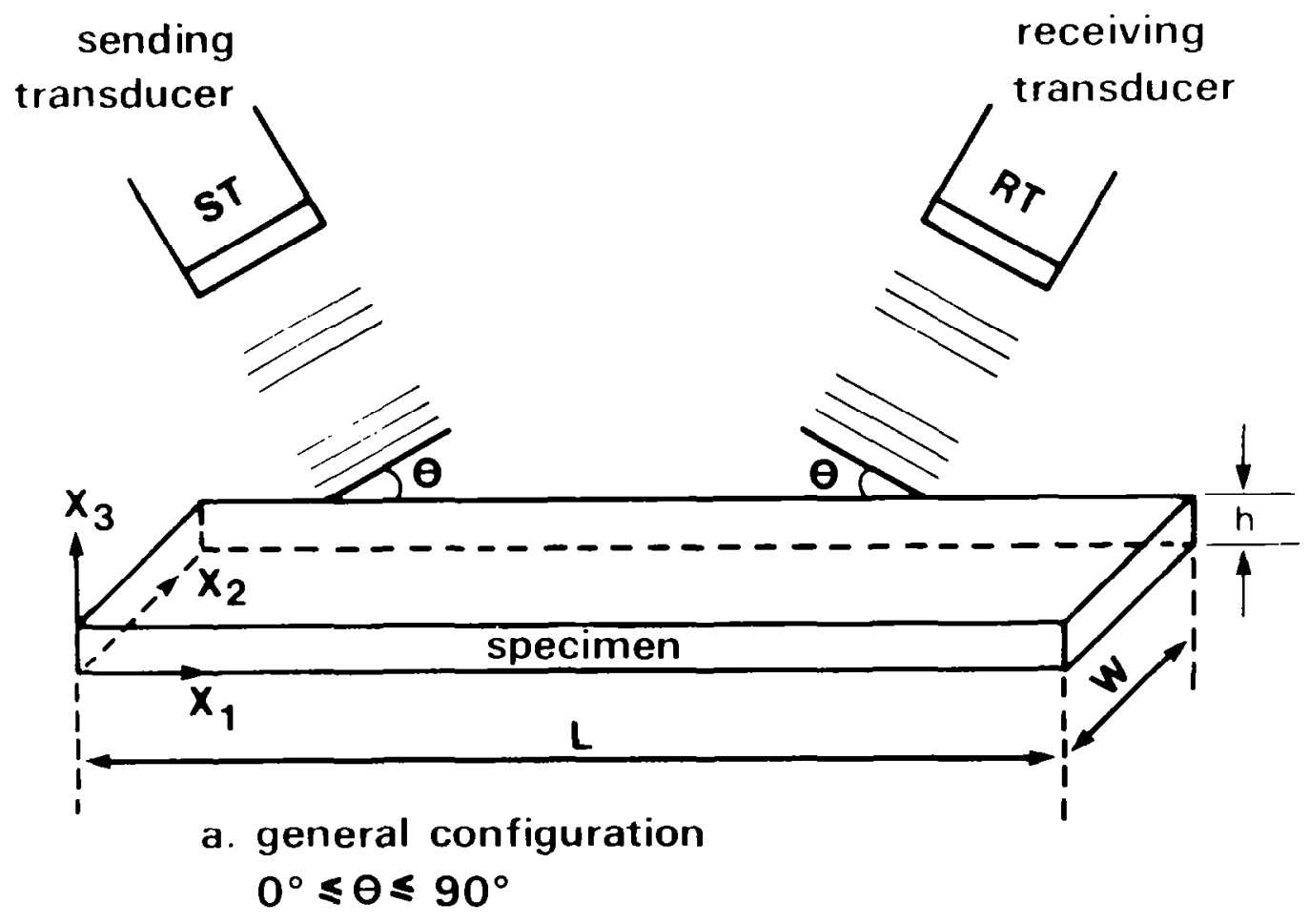

b. axial incidence

$\theta=90^{\circ}$

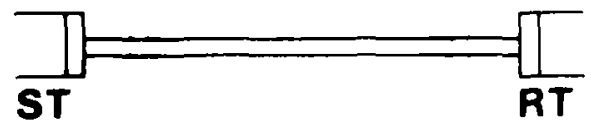

c. normal incidence $\theta=0^{\circ}$

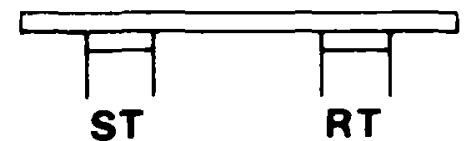

d. oblique incidence $\boldsymbol{\theta}=\boldsymbol{\theta}$

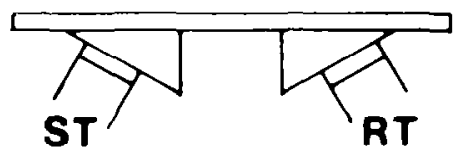

Fig. 22 Transducer Specimen testing configurations. 
An U1tragel II ultrasonic couplant was used between the transducer and the specimen. A very thin coating of couplant was used where effects of thickness of the couplant were neglected. A felt material was used on the backside of the transducer holder to insure that energy did not enter the transducer holder from the specimen.

\subsection{EXPERIMENTAL SYSTEM}

The experimental system is shown in Figure 23; parts of the Arenberg high frequency pulsing system are described below:

Pulsed Oscillator P.G.650.C

The P.G.650.C is a high powered pulsed oscillator which provides a voltage for the sending transducer and produces a narrow band of frequencies which are vital to our measurements since all effects to be measured are frequency dependent. The P.G.650.C possesses a wide frequency range from $.2 \mathrm{MHZ}$ to $190 \mathrm{MHZ}$ with a variable pulse length of 1.5 to 35 usec and delayed trigger action. It has a refined degree of stability and "fine" as well as "coarse" controls on the major variables. It has the flexibility of operation as an independent unit or with triggers and modulation provided by an external source to synchronize with another system of test equipment. Low Frequency Inductance Tuner L.F.T.500

The L.F.T.500 is designed to be used with the pulsed oscillator P.G.650.C using a low frequency current tuned coil. Below $500 \mathrm{Kc}$, the capacitors needed to tune the oscillator would be excessively large; consequently, the inductance is varied in each coil by passing a stable D.C. current through the output winding on the ferrite cores in a manner which does not interfere with the normal operation. Its current range is from $5 \mathrm{Ma}$ to $5 \mathrm{~A}$. Its calibration linearity is $.25 \%$. 


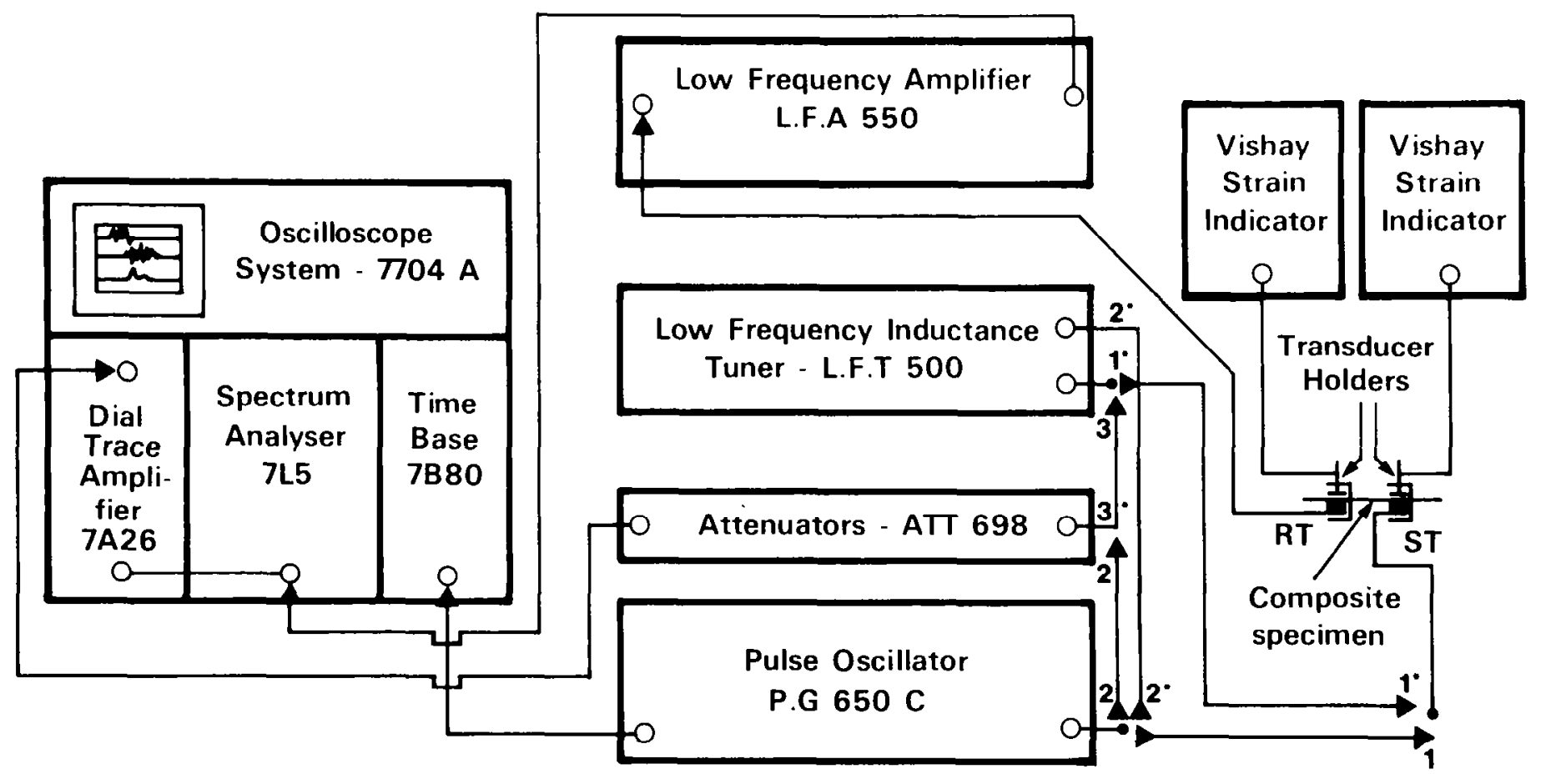

FIG. 23 EXPERIMENTAL SYSTEM.

* The star system was used when frequency

lower than $500 \mathrm{KC}$ was needed.

RT Receiving Transducer

ST Sending Transducer 
Attenuators ATT 698

The attenuator furnish the basis for precision measurement of insertion loss, absorption, etc. in ultrasonic work. The frequency range is from D.C. to beyond $100 \mathrm{MHZ}$.

\subsection{MATERIALS TESTED}

The specimens used were eight-ply graphite-epoxy fiber reinforced composites and aluminum $(6061,2024)$ which was used in the last phase of this work. Physical properties of the specimens are given in Table $X$.

\subsection{PROCEDURE}

An ultrasonic wave was transmitted into the specimen by a sending transducer at an angle of incidence $\theta$ (see Figure 22). At variable distances from the sending transducer in the $x_{1}$ direction and on the same face (except for $\theta=90^{\circ}$ ), a receiving transducer was placed to pick up the transmitted signal at a receiving angle equal to the angle of incidence.

The sending transducer input as well as the receiving transducer output were displayed on the oscilloscope for real time analysis and frequency analysis. Typical input and output signals are shown in Figure 24. 


\begin{tabular}{|c|c|c|c|c|c|c|c|}
\hline Specimen & $\begin{array}{l}\text { Number } \\
\text { Tested } \\
\end{array}$ & $\begin{array}{c}\text { Ply } \\
\text { Angle, deg. }\end{array}$ & $\begin{array}{l}\text { Length, } \\
\mathrm{L}, \mathrm{cm} \\
\end{array}$ & $\begin{array}{c}\text { Thickness } \\
\mathrm{h}, \mathrm{cm}\end{array}$ & $\begin{array}{l}\text { Density } \\
\mathrm{g} / \mathrm{cm}^{3} \\
\end{array}$ & $\begin{array}{l}\text { U1timate } \\
\text { Strength } \\
\text { GPA } \\
\end{array}$ & $\begin{array}{c}\text { Tensile } \\
\text { Modulus } \\
\text { E,GPA } \\
\end{array}$ \\
\hline \multicolumn{8}{|c|}{ Composite* } \\
\hline LVI1K & 1 & {$[0] 8$} & 25.4 & .1384 & 1.584 & 1.24 & 110 \\
\hline LV33H & 1 & {$[0 / \pm 45 / 0] \mathrm{S}$} & 25.4 & . 1355 & 1.355 & .703 & 83.4 \\
\hline LV55 & 1 & {$[ \pm 45] \mathrm{S}$} & 25.4 & .1340 & 1.340 & .181 & 20.1 \\
\hline LV22 & 1 & {$[90] 8$} & 25.3 & .1329 & 1.603 & .0672 & 8.27 \\
\hline Aluminum & & $\begin{array}{l}\text { Width } \\
w, c m\end{array}$ & & & & & \\
\hline 2024 T4 & 2 & $1.27 / 1.57$ & 25.4 & .159 & 2.768 & 4.69 & 73.1 \\
\hline 2024 T4 & 1 & 12.7 & 25.4 & .254 & 2.768 & 4.69 & 73.1 \\
\hline 2024 T4 & 1 & 15.88 & 25.4 & .318 & 2.768 & 4.69 & 73.1 \\
\hline 6061 T0 & 1 & 25.4 & 8.11 & .081 & 2.713 & 1.17 & 68.95 \\
\hline $6061 \mathrm{T4}$ & 1 & 25.4 & 16.0 & .159 & 2.713 & 2.41 & 68.95 \\
\hline 6061 T4 & 1 & 25.4 & 11.4 & .229 & 2.713 & 1.17 & 68.95 \\
\hline
\end{tabular}

TABLE $X$ - PHYSICAL PROPERTIES OF THE SPECIMENS

* after Vary ${ }^{8}$ 


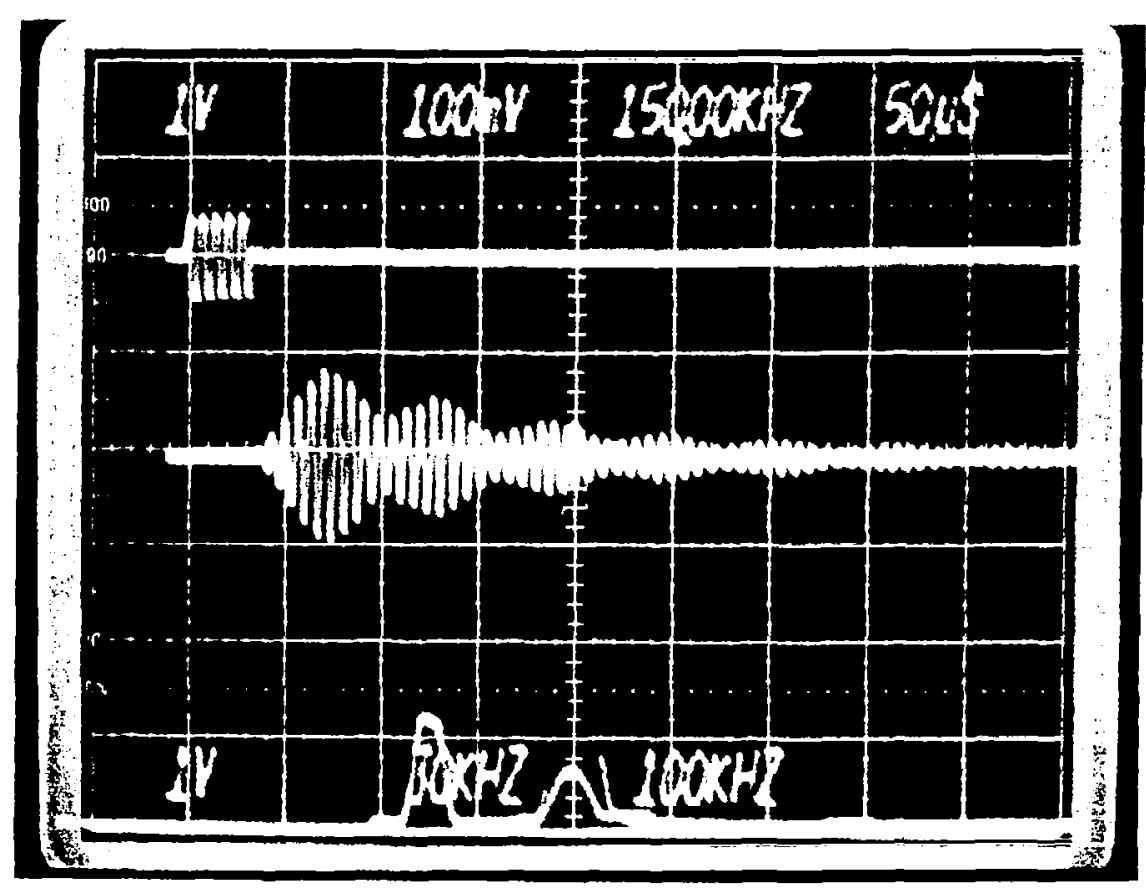

FIG. 24 TYPICAL INPUT AND OUTPUT SIGNALS AND THEIR CORRESPONDING FREQUENCIES FOR LVIIK. 


\section{CHAPTER III}

\section{EXPERIMENTAL RESULTS}

Experimental results are presented in this chapter for the dispersion phenomenon for the four composite specimens LVTIK, LV33H, LV55, and LV22 in the case of normal incidence i.e. $0=0^{\circ}$ and in the case of axial incidence i.e. $\theta=90^{\circ}$. A discussion and list of advantages of using plastic wedges in the case where $0^{\circ}<\theta<90^{\circ}$ wi 11 be presented. And finally the results of the testing of the Arenberg ultrasonic system in detecting Lamb-wave in aluminum $(2024,6061)$ in the axial incidence case wil1 be presented.

\subsection{DISPERSION IN THE CASE OF NORMAL INCIDENCE}

Wave speed measurements were recorded as waves of different frequencies ( $f=.75-3.0 \mathrm{MHZ}$ ) were traversing the four composite specimens. A graph was plotted showing speed versus frequency for the four composite specimens under study in figure 25. The graph shows that the wave velocity is frequency dependent for all four specimens.

The bulk velocities for LVIIK and LV22 are approximately $850 \mathrm{~cm} / \mathrm{ms}$ and $100 \mathrm{~cm} / \mathrm{ms}$ respectively. By comparing these values to the velocities recorded and presented in Figure 25 for LVIIK and LV22, one can see that the corresponding wave velocities were higher than the bulk velocity for the same material. This is explained by the presence of Lamb waves. For the specimens LVIIK and LV22 the dispersion data revealed the existence of higher modes of wave propagation. In order to define these higher modes plexiglass wedges $\left(0^{\circ}<\theta<90^{\circ}\right)$ were used. 


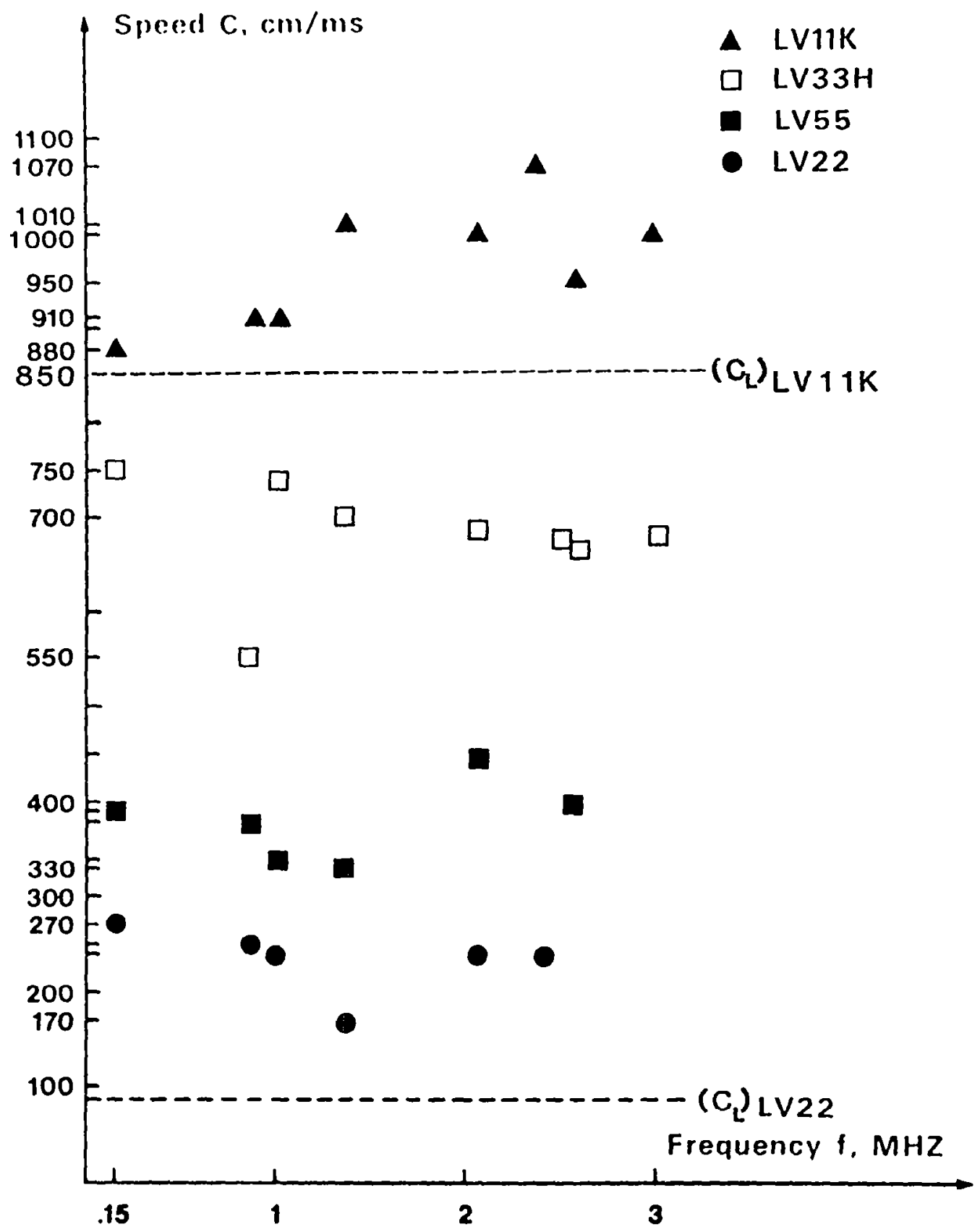

Fig. 25 Wave speed vs. frequency for composites with normal incidence transducer arrangement. 
3-2 THE USE OF PLASTIC WEDGES FOR $0^{\circ}<\theta<90^{\circ}$

Plona, Behravesh, and Mayer 22 have shown that the phase velocity of Lamb waves may be controlled by setting the angle of incidence of an immersing longitudinal wave as shown in Figure $22 a$; i.e. by varying $\theta$. This may be done by immersing the transducer in liquid, in air, or by using a plastic wedge. 10,15 and 30 degrees plastic wedges were made and tried in this research, but evidence is presented only for the $15^{\circ}$ wedge. Great difficulty was encountered in attempting to hold the wedges properly. Wave velocity data was not collected, but qualitative evidence of the value of using wedges will be noted.

Figure 26 compares three oscilloscope time and frequency traces; the material is LVIIK and the frequency is approximately $1 \mathrm{MHZ}$. The input signal is always the wave in the upper left hand corner of the trace. The top trace shows the output for normal incidence $\left(\theta=0^{\circ}\right)$ where the effects of constructive and destructive interference are seen due to the multiple reflections across the thickness of the specimens. The output trace appears as a modulated wave and is clearly quite different in form or shape from the input wave. It is also probable that multiple modes and end reflections are present. The middle trace shows the output for axial incidence $\left(\theta=90^{\circ}\right)$ where the effects of multiple modes and end reflections are present. The output is once again quite different in form and shape from the input. The bottom trace shows the output when a $15^{\circ}$ plastic wedge is used. In this case the output wave has almost exactly the same shape and form as the input wave, i.e., the time duration is $30 \mu \mathrm{sec}$ and the amplitude is constant. It is believed that the wedge method eliminates the constructive/destructive 


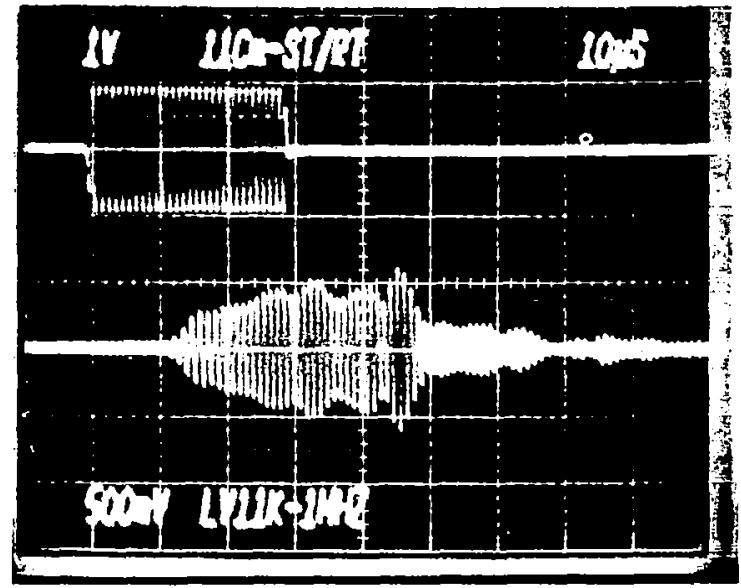

a. NORMAL INCIDENCE

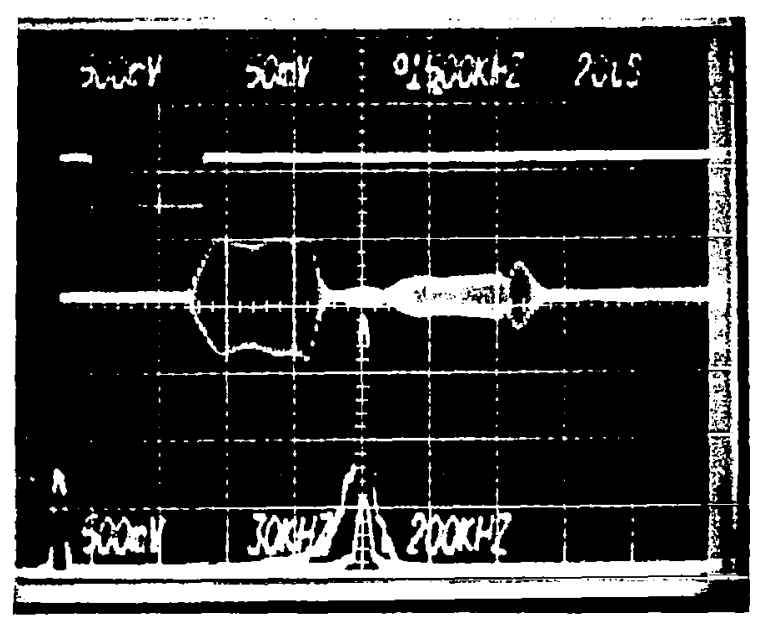

b. AXIAL INCIDENCE

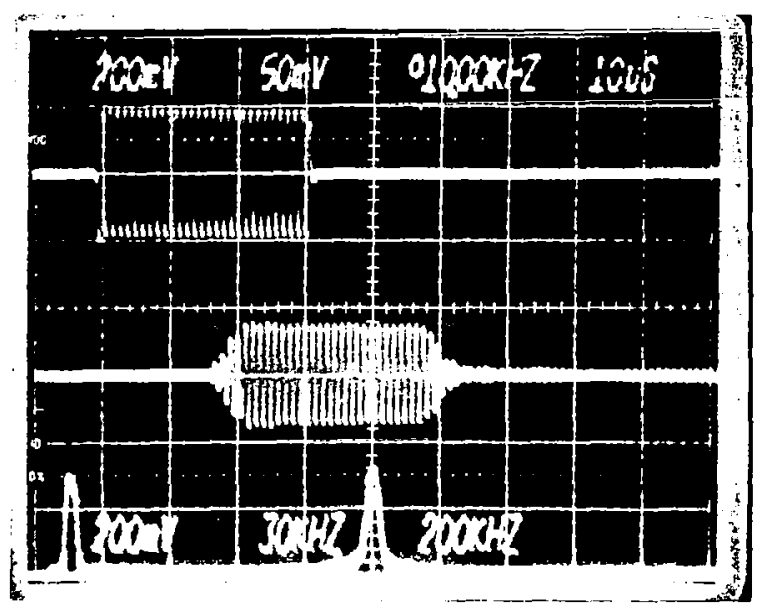

c. OBLIQUE INCIDENCE

15 WEDGE

FIG. 26 - TRACES SHOWING WEDGE EFEECT VERSUS NONWEDGE EFFECT 
interferences effect, the multiple mode problem, and the end reflection waves.

Figure 27 shows how the wedge eliminated a problem which frequently occurred for frequencies greater than $1 \mathrm{MHZ}$; electromagnetic waves were often transmitted when the transducer was in direct contact with the specimen; the material is LVIIK and the frequency is approximately $2.5 \mathrm{MHZ}$. The top trace shows the output for axial incidence $\left(\theta=90^{\circ}\right)$ where two different waves are present, one wave arriving instantenously and the other wave arriving later. The first arrival is an electromagnetic wave whose speed is obviously too great to measure. The second arrival is the mechanical wave response for the input wave. The output signal shown in the lower trace, where a $15^{\circ}$ wedge was used, shows no evidence of an electromagnetic wave.

\section{3-3 AXIAL INCIDENCE WAVES, $\theta=90^{\circ}$}

This section describes how the lowest order symmetric Lamb waves are propagated along the axial direction $\left(x_{1}\right)$ of the four composite specimens. In I.Figure $28 \mathrm{C}$ versus fh was plotted for all four specimens, where $C$ is the velocity of the stress wave, $f$ is the frequency of the propagating wave, and $h$ is the thickness of the specimen.

Figure 28 only presents a small portion of the total possible dispersion curves for this material. Habeger, Mann, and Baum ${ }^{22}$ have developed a theory which may be used to construct dispersion curves for the $0^{\circ}$ degree (LVIIK) and the $90^{\circ}$ (LV22) unidirectional laminates. The authors of this report are not able to construct these curves at this time because we do not have the specimens necessary to conduct tests to measure material constants needed for 


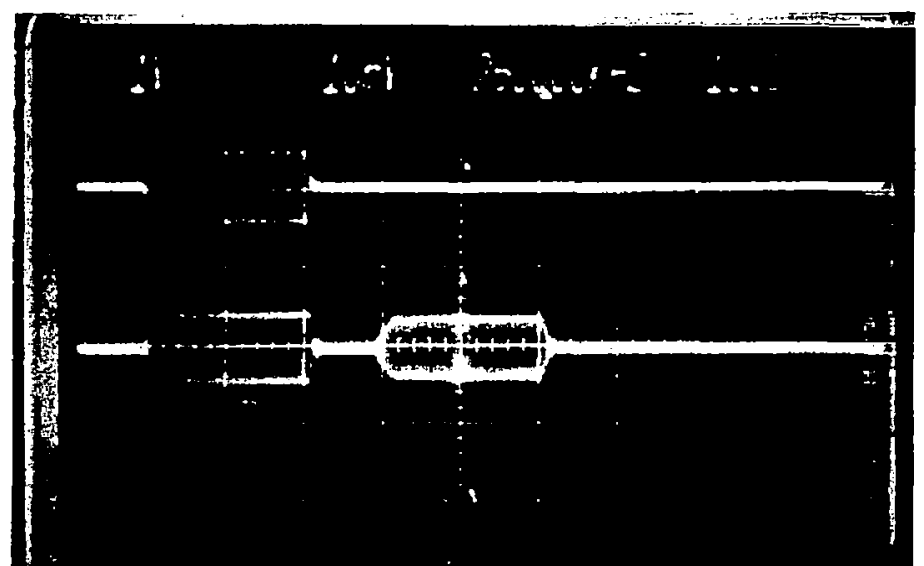

a. AXIAL INCIDENCE
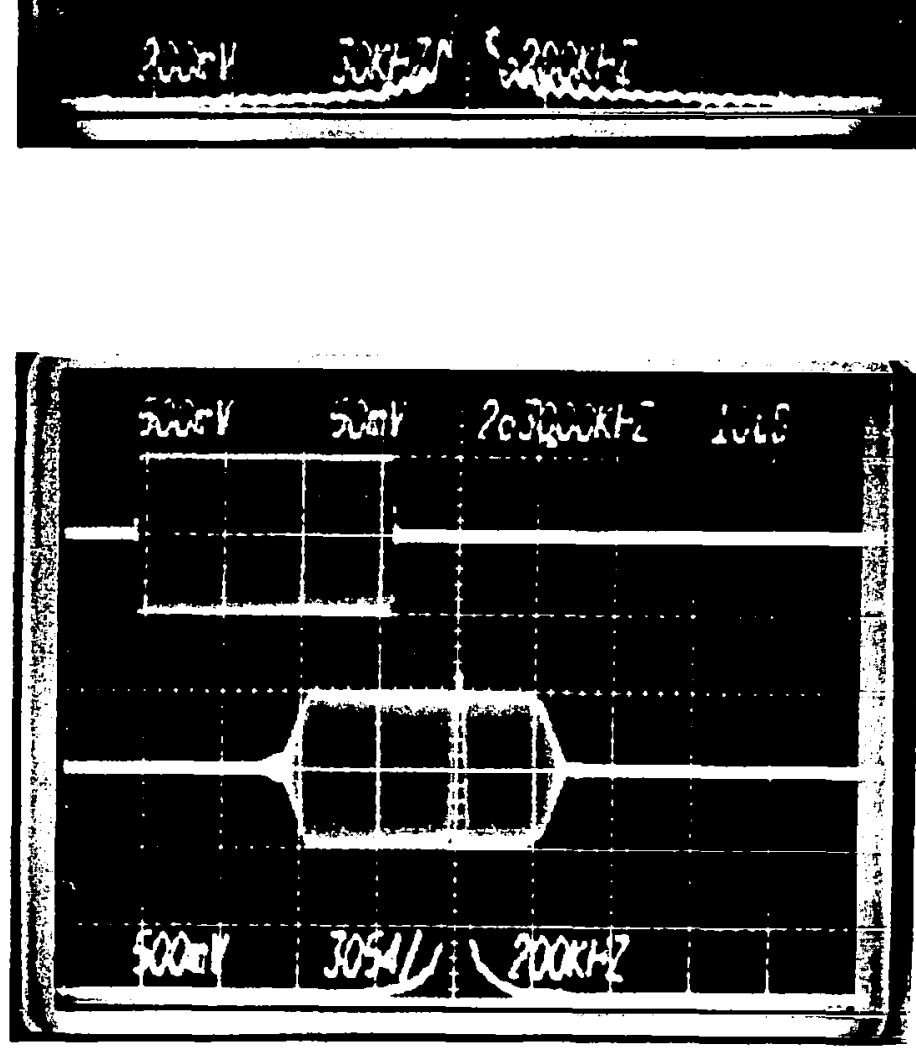
b. OBLIQUE INCIDENCE
15 WEDGE

FIG. 27 - TRACES SHOWING THE WEDGE EFFECT IN ELIMINATING ELECTROMAGNETIC WAVES • 


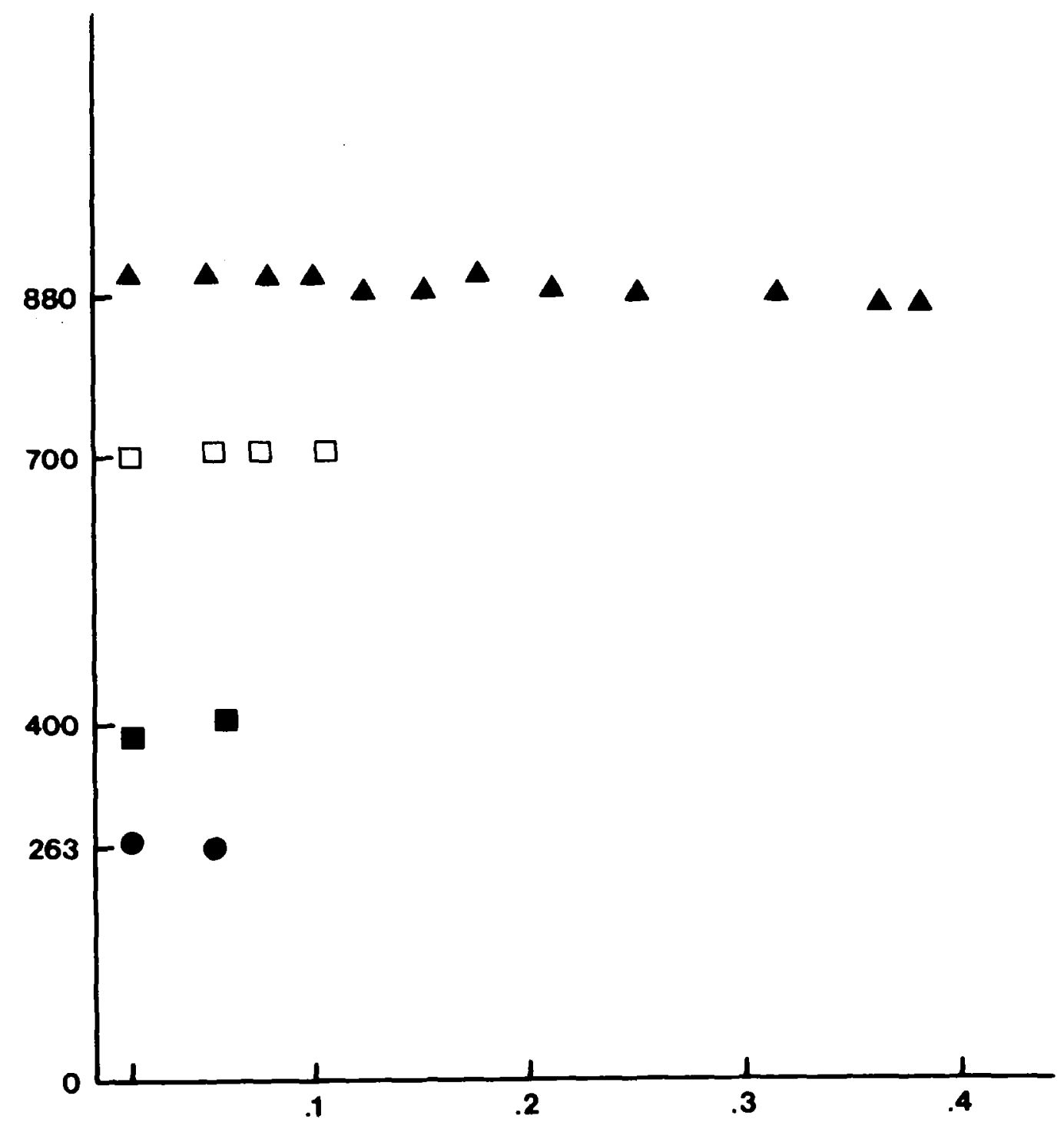

fh, $\mathrm{MHZ}-\mathrm{cm} \rightarrow$

Fig. $28 \mathrm{C}$ vs. fh for axial incidence wave, $\theta=90^{\circ}$.
$\Delta \quad$ LV11K
ㄴ. LV33H
- LV55
- LV22 
the theory. It is our belief that the data presented in Figure 28 would lie on the initial portion of the lowest order symmetric mode. Note the largest value of fh plotted on the abscissa is $0.4 \mathrm{MHZ}-\mathrm{cm}$. The thickness for these specimens is approximately $0.13 \mathrm{~cm}$ and the maximum available frequency for testing is $3.0 \mathrm{MHZ}$; the frequency is limited by the available transducers. The data for LV11K shows a slight decrease as the product fh increases; this is consistent with the results reported by Habeger, Mann, and Baum ${ }^{22}$. A limited amount of data is available for LV33H, LV55, and LV22 because of great energy dissipation with increasing frequencies over the long length of the specimen.

\section{3-4 LAMB WAVE PROPAGATION IN ALUMINUM}

Lamb wave propagation in aluminum was studied to demonstrate that our experimental system and methodology was working and was in agreement with the analytical results ${ }^{14}$, in particular we studied axial incidence $\left(\theta=90^{\circ}\right)$ waves and compared them with theory.

The data was plotted on $C$ versus fh curves from the work done by Worlton 18 for aluminum plate, and is presented in Figures 29 and 30. Aluminum specimens of five different thicknesses were used in order to generate more data points.

It is not possible to draw physically correct curves through the data points without the aid of an analytical theory. If one removes the families of curves (modes), the experimental data appears randomly scattered.

Because the experimental results reported for aluminum using the Arenberg systems are in agreement with existing theory and experiment, it may be concluded that the system is functioning correctly and that Lamb wave 


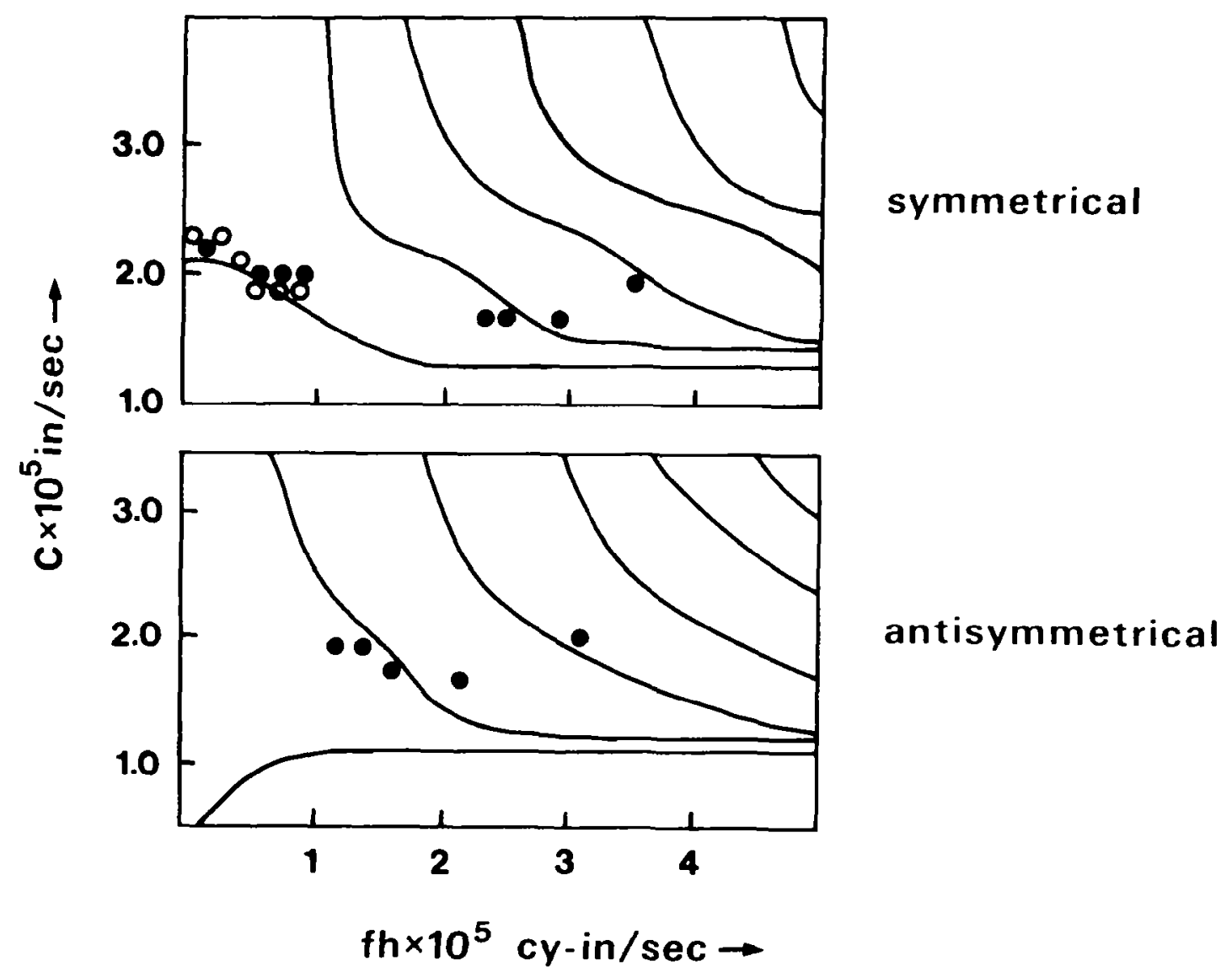

Fig. 29 Lamb wave propagation in aluminum (6061).

$$
\begin{array}{ll}
- & h=.09 \text { in } \\
\circ & h=.032 \text { in }
\end{array}
$$




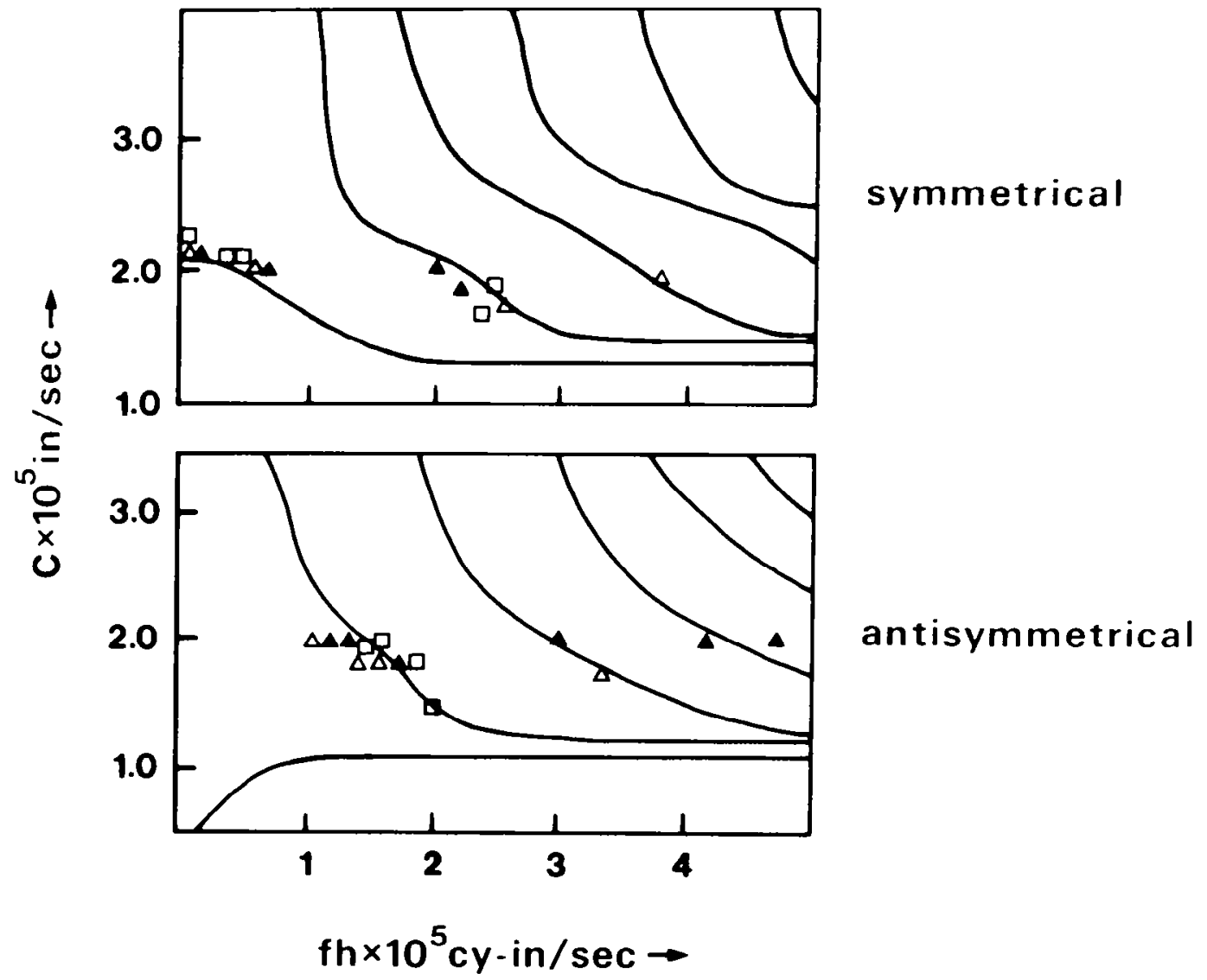

Fig. 30 Lamb wave propagation in aluminum (2024).

$\triangle \mathrm{h}=.125 \mathrm{in}$

$\Delta h=.100 \mathrm{in}$

व $h=.0625 \mathrm{in}$ 
propagation exists in specimens where thickness is of the order of the composite specimen thickness and hence it is correct to assume Lamb waves are propagating in the composites. It is also apparent that an analytical theory must be used to develop dispersion curves for composites before the composite data may be plotted. 
CHAPTER IV

\section{CONCLUSION}

The data collected for the aluminum and composite specimens clearly demonstrate that Lamb wave propagation is the mode of propagation in existence for all angles of incidence.

A theory is available which may be applied to homogeneous orthotropic materials which, for this study, were the $0^{\circ}$ degree and the $90^{\circ}$ degree graphite-epoxy fiber reinforced composite. Additional specimens and testing are needed to apply the theory. The $[0 / \pm 45 / 0] \mathrm{s}$ and the $[ \pm 45]$ s graphite-epoxy fiber reinforced composite which are not homogeneous orthotropic materials will require a more advanced theory.

Plastic wedges appear to be a feasible way of sending and receiving Lamb waves at oblique incidence, but more work must be done on constructing a device to hold transducers and wedges at arbitrary angles. 


\section{BIBLIOGRAPHY}

1. Sokolov, S., "Ultrasonic 0scillations and their Application," Tech Physics, U.S.S.R. 2, p 522 (1935).

2. Firestone, F.A., "Supersonic reflectoscope, an instrument for inspecting the interior of solid parts by means of sound waves," JASA 17 (1945) pp 287-299.

3. Truel1, R. and Hikata, A., "Fatigue and U1trasonic Attenuation," Symposium on Nondestructive Testing, Los Angeles, Calif., Sept. 17 and 18, 1956, American Society for Testing Materials, ASTM STP No. 213, Philadelphia, PA, 1957, pp 63-39.

4. Levitt, A.P. and Martin, A.G., "Ultrasonic Determination of Elastic Constants of Metals at Elevated Temperatures," Non Destructive Testing, Vol. 18, No. 5, Sept. 1960, pp 333-336.

5. Erman, Donald, "Ultrasonic Pulse-Echo Techniques for Evaluating Thickness, Bonding and Corrosion," Non Destructive Testing, Vol 18, No. 6, Nov. 1960, pp 408*410.

6. Vary, A., and Bowles, K.J., "U7trasonic Evaluation of the Strength of Unidirectional Graphite-Polyimide Composites, "NASA Technical Memorandum TM-73646, Apri1, 1977.

7. Vary, A. and Bowles, K.J., "Use of an U1trasonic-Acoustic Technique for Nondestructive Evaluation of Fiber Composite Strength," NASA Technical Memorandum TM-73813, Feb, 1978.

8. Vary, A. and Lark, R.F., "Correlation of Fiber Composite Tensile Strength with the U1trasonic Stress Wave Factor," NASA Technical Memorandum TM-78846, April, 1978.

9. Vary, A., "Correlations Among U1trasonic Propagation Factors and Fracture Toughness Properties of Metallic Materials," Materials Evaluation, Vol. 36, No. 7, June 1978, pp 55-64.

10. Vary, A., "Quantitative U1trasonic Evaluation of Mechanical Properties of Engineering Materials," NASA Technical Memorandum TM-78905, June, 1978.

11. Vary, A., "Correlations Between U1trasonic and Fracture Toughness Factors in Metallic Materials," NASA Technical Memorandum TM-73805, June, 1978.

12. Williams, Jr. J.H. and Dol1, B., "Ultrasonic Attenuation as an Indicator of Fatigue Life of Graphite/Epoxy Composites," NASA CR-3779, 1979.

13. Williams, Jr. J.H., Nayeb-Hashemi, H. and Lee, S.S., "U1trasonic Attenuation and Velocity in AS/3501-G Graphite/Epoxy Fiber Composite,"NASA Contractor Report 3180, December, 1979. 
14. Lamb, H.,"On Waves in an Elastic Plate," Proc. Rog. Soc. A.93, $114-28$ (1917).

15. Meeker, T.R., and Meitzler, A.H., "Guided Wave Propagation in Elongated Cylinders and Plates," Physical Acoustics, edited by Mason, Warren P., Academic Press, New York and London, 1964, Part A, pp 112-166.

16. Kolsky, H., Stress Waves in Solids, New York, 1963, pp 16.

17. Vitorov, I.A., Rayleigh and Lamb Waves, Plenum Press, New York, pp 67-117 (1967).

18. Woriton, D.C., "Experimental Confirmation of Lamb Waves at Megacycle Frequencies," J. Appl. Phys., 32(6): 967-971 (1961).

19. Meitzler, A.H., J. Acoust. Soc. Am. 33, 435-445 (1961).

20. Habeger,C.C., Mann, R. W., and Baum, G.A. "Ultrasonic Plate Waves in Paper," Uitrasonics, March 1979, pp 57-62.

21. Firestone, F.A., Non-Destructive Testing, 7, No. 2, 5 (1948).

22. Plona, T.J., Behravesh, M., and Mayer, W.G., "Rayleigh and Lamb Wave at Liquid-Solid Boundaries," U1 trasonics, JuTy 1975, pp 171-174.

23. Baaklini, Y.G., "Ultrasonic Evaluation of a "0" Degree Graphite-Epoxy Composite Under Tensile Loading," M.S. Thesis, Department of Civil Engineering, C.S.U., December 1981. 


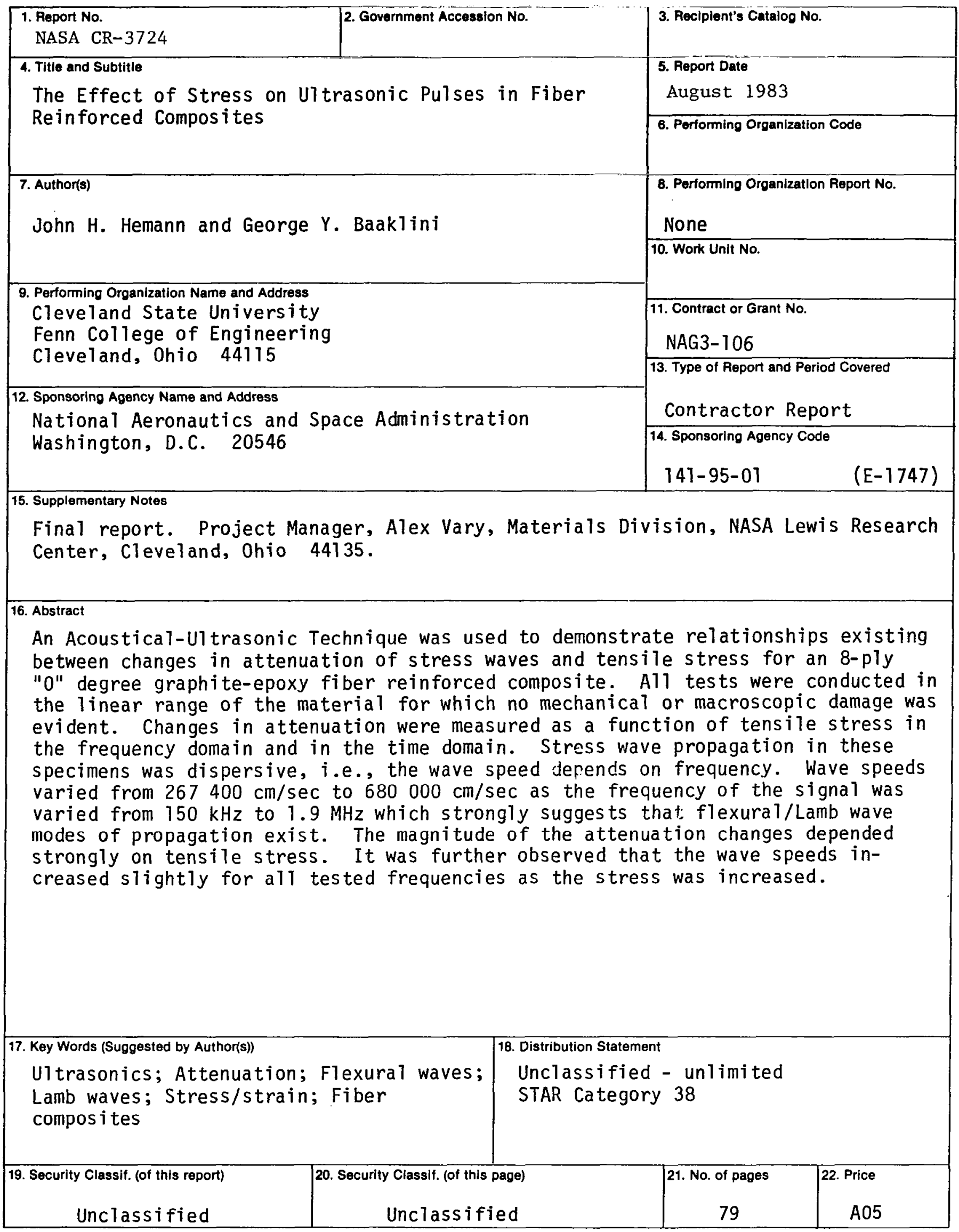

For sale by the National Technical Information Service. Springfield, Virginia 22161 